TAO, Vol. 15, No. 3, 437-467, September 2004

\title{
Stress-Induced Changes in the Electrical Conductivity of Igneous Rocks and the Generation of Ground Currents
}

\author{
Friedemann T. Freund ${ }^{1}{ }^{*}$, Akihiro Takeuchi ${ }^{2}$, Bobby W. S. Lau ${ }^{2}$, Rachel Post ${ }^{2}$, \\ John Keefner ${ }^{3}$, Joshua Mellon ${ }^{4}$, and Akthem Al-Manaseer ${ }^{5}$
}

(Manuscript received 10 March 2004, in final form 27 June 2004)

\begin{abstract}
If we can ever hope to understand the non-seismic signals that the Earth sends out before major earthquakes, we need to understand the physics of rocks under increased levels of stress. In particular we need to understand the generation of electrical currents in the ground. We have begun to study how electrical conductivity of igneous rocks changes under stress and what types of charge carriers are involved. We show that quartz-rich granite and quartz-free anorthosite both generate electronic charge carriers when subjected to stress. The charge carriers are positive holes (p-holes), i.e., defect electrons on the oxygen anion sublattice. They spread out of the stressed rock volume, the "source volume", into the surrounding unstressed rocks. Time-varying ground currents are required to generate pre-earthquake local magnetic field anomalies and low-frequency electromagnetic emissions. We posit that stress-induced activation of p-hole charge carriers and their outflow from the source volume is the basic process by which ground currents can be generated in the Earth's crust. We propose that the arrival of p-holes at the Earth's surface leads to changes in the ground potential that may induce ionospheric perturbations. We further propose that the build-up of high electric fields at the ground surface can ionize the air, hence cause ion emission and corona discharges. When p-holes recombine at the ground surface, they are expected to form vibrationally highly excited $\mathrm{O}-\mathrm{O}$ bonds. The de-excitation of these $\mathrm{O}-\mathrm{O}$ bonds will lead to stimu-
\end{abstract}

1 Goddard Earth Science Technology Center (GEST), University of Maryland Baltimore County, on leave from Department of Physics, San Jose State University, San Jose CA 95112-0106, and NASA Ames Research Center, Earth System Science and Technology Branch, Moffet Field, CA 94035-1000, USA.

2 Department of Physics, San Jose State University, San Jose CA 95112-0106, USA.

3 South Dakota School of Mines \& Technology, Rapid City, SD 57701, USA.

${ }^{4}$ Oregon State University, Department of Physics, Corvallis, OR 97331-4501, USA.

5 San Jose State University, Department of Civil Engineering, San Jose, CA 95192-0039, USA.

* Corresponding author address. Friedemann T. Freund, NASA Goddard Space Flight Center, Geodynamics Branch, MS 921, Greenbelt, MD 20771, USA; E-mail: ffreund@core2.gsfc.nasa.gov 


\section{lated mid-IR emission, which may explain the reported pre-earthquake "thermal anomalies" identified in satellite images.}

\section{(Key words: Pre-earthquake phenomena, Electrical conductivity, Stress, Magnetic field, Ionization, EM emission, Thermal anomalies)}

\section{INTRODUCTION}

\subsection{Electronic Charge Carriers in Rocks}

Many pre-earthquake phenomena require electrical currents that flow in the ground. This is particular true for low to very low frequency electromagnetic (EM) emissions and magnetic field anomalies that have been reported from many regions of the world to precede earthquakes and seaquakes. Since such EM emissions and magnetic field anomalies have been detected over long distances (Dea et al. 1993, 1997; Molchanov et al. 1998a; Ismaguilov et al. 2001; Ohta et al. 2001) and from satellite altitudes (Serebryakova et al. 1992; Molchanov et al. 1998b, c; Parrot 1994), ground currents must be quite strong. This raises the question about mechanisms that can generate powerful electrical currents in the ground.

Most researchers have discussed EM emissions and magnetic field anomalies in the context of piezoelectric effects (Finkelstein et al. 1973; Nitsan 1977; Cress et al. 1987; Yoshida et al. 1994, 1998) or triboelectrification (Yamada et al. 1989; Molchanov and Hayakawa 1998a; Takeuchi and Nagahama 2001). Another suggestion that has been considered is based on streaming potentials. Streaming potentials arise from charge separation when water or brines are pushed through porous rocks or along gouge-filled faults (Morgan et al. 1989; Yamada et al. 1989; Bernabé 1998; Lonre et al. 1999; Revil et al. 1999). In this case the charge carriers are ions in aqueous solution.

Here we follow a different lead. We look at the stress-induced activation of electronic charge carriers in rocks. Before we address this issue we need to answer a rather basic question: What types of electronic charge carriers are known to exist in silicate rocks?

As Fig. 1 shows there are two types of electronic charge carriers that can exist in solids: electrons and defect electrons. Our attention focuses on defect electrons. Defect electrons arise when an electron is lacking at a given site in the crystal structure where one is supposed to be. Defect electrons are electronic positive charge carriers, also known as holes. They play a central role in semiconductors (Kittel 1980).

Semiconductors are materials, where the energy difference between the valence band and the conduction band, the band gap energy $E_{g}$, is so narrow that $k T$, the mean thermal energy (with $\mathrm{T}$ being the temperature in degrees Kelvin and $\mathrm{k}$ the Boltzmann constant) is enough to lift electrons from the valence band into the conduction band. For each electron lifted to the conduction band, a hole is left in the valence band. Both act as charge carriers but electrons in the conduction band are much more mobile than holes in the valence band. Therefore, with conductivity being given by the number of charge carriers (electrons and holes) multiplied by their respective mobilities, every chemically pure, intrinsic semiconductor is n-type, meaning 


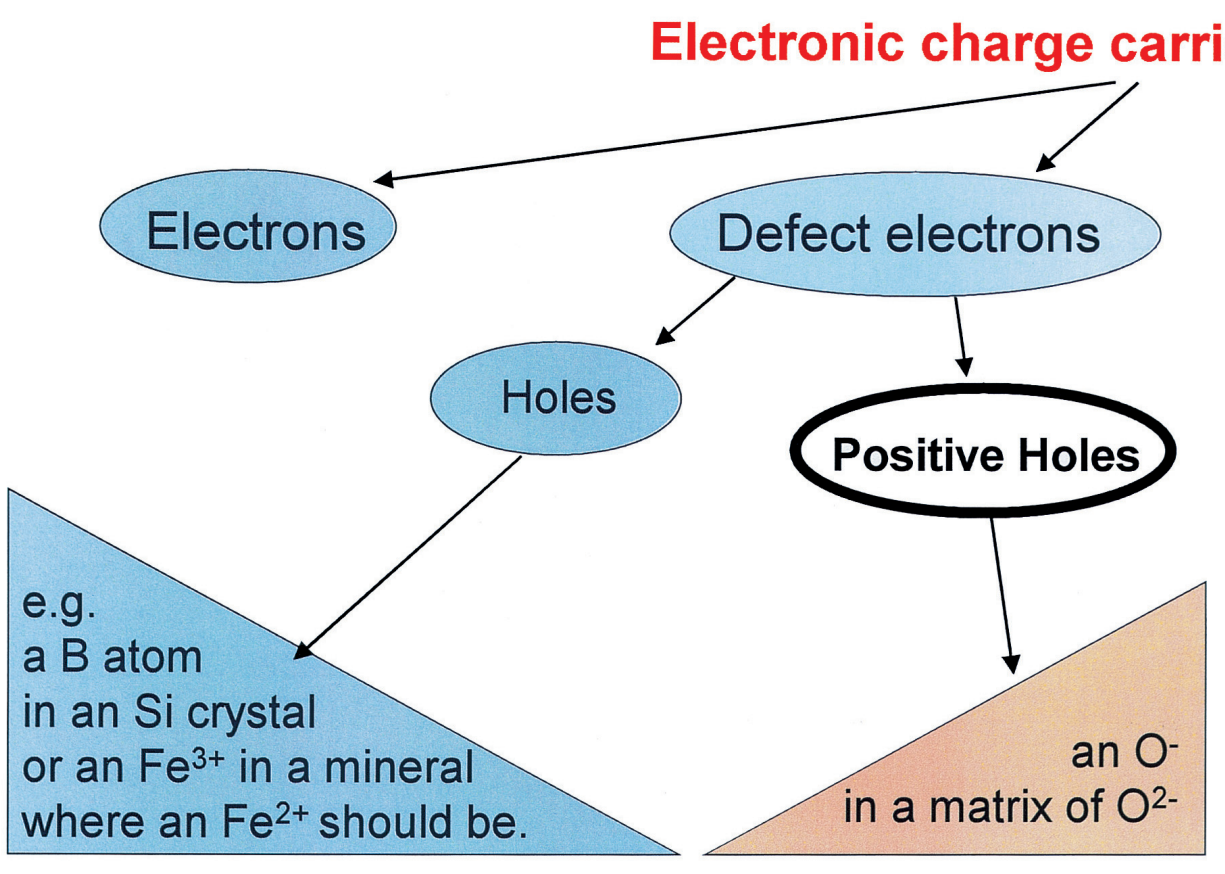

Fig. 1. Two types of electronic charge carriers exist in solids, electrons and defect electrons or holes. Holes can exist in various lattice environments. When they occur in the oxygen anion sublattice of oxide and silicates they are called positive holes or $\mathrm{p}$-holes for short.

that its electrical conductivity will always be dominated by the electrons in the conduction band. To make a semiconductor p-type, so that holes dominate its conductivity, specific impurities have to be introduced, which add holes without adding electrons.

A classical example of a p-type semiconductor is silicon doped with B atoms that occupy $\mathrm{Si}$ sites. Since boron has only three outer valence electrons compared to silicon's four, the substitution produces an electron-deficient site, commonly called a "hole". The hole is not strictly localized at the B atom. Instead B acts as an acceptor, allowing valence band electrons from neighboring Si to flow onto the B site. Conversely, the hole spreads out from the B site over the neighboring Si sites and thereby turns into a positive charge carrier. B-doped silicon is a p-type semiconductor when the number of holes in the valence band (made large by Bdoping) multiplied by their mobility exceeds the number of electrons in the conduction band multiplied by their mobility (Kittel 1980).

Insulators differ from semiconductors in the width of their band gaps. In insulators the band gap is so wide that thermal promotion of valence band electrons into the conduction band becomes practically impossible. 
As a rule minerals are insulators. Exceptions showing relatively large electronic conductivity are magnetite, $\mathrm{Fe}_{3} \mathrm{O}_{4}$ (Dieckmann et al. 1983) and some sulfides (Park 2002). Holes can exist in silicate minerals, for instance when a trivalent cation such as $\mathrm{Fe}^{3+}$ occupies a cation site structurally designed for a divalent cation such as $\mathrm{Fe}^{2+}$. In these cases, however, the hole state tends to be localized on the $\mathrm{Fe}^{3+}$ site, meaning that it is not mobile and does not contribute significantly to the conductivity.

Of course, at high temperatures all rocks become conductive because ions, mostly cations, start to become mobile (Hermance 1979; Matsushima 1989). The problem is how to understand the non-zero conductivity of rocks at low to moderate temperatures. Duba and Shankland (1982) proposed that carbon precipitates in igneous and high-grade metamorphic rocks from high-temperature, high - pressure, $\mathrm{CO}_{2}$ - laden fluids, producing intergranular carbon films. Such films would persist long after the $\mathrm{CO}_{2}$ - laden fluids are gone and the rocks have cooled. If interconnected and partially graphitized, they would conduct currents due to electrons making their way along grain boundaries.

Intergranular carbon films have been invoked to account for the small, conductivity of crustal rocks (Frost et al., 1989; Glover and Vine 1992, 1994). The conductivity of carbon films is sometimes combined (Shankland et al. 1997) with electrolytical conductivity that would arise when water and brines fill fissures and cracks in porous rocks (Chelidze and Gueguen 1999).

\subsection{Positive Holes}

We are looking at an entirely different class of charge carriers in rocks. They are electronic but have been entirely overlooked in the past.

The formulae of oxides and silicates minerals are invariably written with the tacit assumption that their oxygen anions exist in nothing but the 2- oxidation state. However, oxygen anions can exist in two oxidation states: 2- and 1-. Any oxygen in the $\mathrm{O}^{-}$state occupying a site that is crystallographically assigned to $\mathrm{O}^{2-}$ represents an electronic hole. To distinguish holes in the $\mathrm{O}^{2-}$ sublattice from other types of holes, they are called "positive holes" or p-holes for short.

Positive holes reside in the $\mathrm{O} 2 \mathrm{p}$-dominated valence band of the silicate minerals, where $2 p$ denotes the electronic levels derived from the $2 p$ electronic orbitals of atomic oxygen using the usual symbolic representation of s, p, d, etc. Being electronic in nature and probably highly delocalized (Freund et al. 1994), p-holes travel at the upper edge of the valence band. They are not stopped by grain boundaries. The reason is that all silicate minerals have $\mathrm{O} 2 \mathrm{p}$-dominated valence bands, which are in electronic contact. Hence, p-holes should be able to jump grain boundaries with relatively little scattering or attenuation (Freund 2002, 2003). They should be able to traverse macroscopic distances. Indeed, once activated, positive voltage signals have been observed to propagate through rocks at speeds in the order of $100-300 \mathrm{~m} \mathrm{~s}^{-1}$, probably due to a phonon-assisted p-hole hopping mechanism from $\mathrm{O}^{2-}$ to $\mathrm{O}^{2-}$ lattice site (Freund 2002). With lattice phonon frequencies in the order of $10^{12} \mathrm{~Hz}\left(\mathrm{sec}^{-1}\right)$ and jump distances from $\mathrm{O}^{2-}$ to $\mathrm{O}^{2-}$ lattice sites in the order of $3 \AA\left(10^{-10} \mathrm{~m}\right)$, such a speed of propagation of the wave front appears reasonable: $3 \cdot 10^{-10} \mathrm{~m} \times 10^{12} \mathrm{sec}^{-1} \approx 300 \mathrm{~m} \mathrm{~s}^{-1}$. The drift velocity, the speed 
with which p-holes actually move as individual charge carriers in a given electric field, is certainly much smaller but currently still unknown.

The reason why p-holes had not been previously recognized as potentially importance charge carriers is probably due to the fact that, under normal conditions, they exist in a dormant form, in the form of positive hole pairs, PHP (Freund 2002, 2003). Such PHPs are chemically equivalent to peroxy bonds, $\mathrm{O}^{-}-\mathrm{O}^{-}$, characterized by a very short $\mathrm{O}^{-}-\mathrm{O}^{-}$distance of $\sim 1.5 \AA$ compared to the usual $\mathrm{O}^{2-}-\mathrm{O}^{2-}$ distances ranging from $2.7 \AA$ to $2.9 \AA$. Peroxy bonds are known defects in fused silica (Friebele et al. 1979; Ricci et al. 2001) and natural quartz (Fukuchi 1996). In silicate minerals they are believed to link $\mathrm{XO}_{4}$ tetrahedra, $\mathrm{O}_{3} \mathrm{X} /{ }^{\mathrm{OO}} \backslash \mathrm{XO}_{3}$, where $\mathrm{X}=\mathrm{Si}^{4+}, \mathrm{Al}^{3+}$, etc.

\subsection{How p-Holes are Introduced into Minerals and Rocks}

We can be reasonably certain that PHPs and, hence, p-holes are introduced into oxides and silicates via the structural incorporation or "dissolution" of small amounts of water during crystallization or recrystallization in $\mathrm{H}_{2} \mathrm{O}$ - laden environments.

There is general agreement in the literature that, when minerals crystallize in $\mathrm{H}_{2} \mathrm{O}$ laden environments, including $\mathrm{H}_{2} \mathrm{O}$ - saturated magma, small but non-negligible amounts of $\mathrm{H}_{2} \mathrm{O}$ become structurally incorporated even in minerals, which are nominally anhydrous such as feldspars, quartz, pyroxenes, garnets, and olivines (Wilkins and Sabine 1973; Bell and Rossman 1992; Rossman 1996). The dissolved $\mathrm{H}_{2} \mathrm{O}$ does not stay in the form of molecular $\mathrm{H}_{2} \mathrm{O}$ but turns into hydroxyls, $\mathrm{O}_{3} \mathrm{X}-\mathrm{OH}$ with $\mathrm{X}=\mathrm{Si}^{4+}, \mathrm{Al}^{3+}$, etc. Writing this reaction for a silicate with $\mathrm{XO}_{4}$ tetrahedra linked via corners, we have: $\mathrm{O}_{3} \mathrm{X} /{ }^{\mathrm{O}} \backslash \mathrm{XO}_{3}+\mathrm{H}_{2} \mathrm{O} \Rightarrow \mathrm{O}_{3} \mathrm{X} /{ }^{\mathrm{OH}}{ }_{\mathrm{HO}} / \mathrm{XO}_{3}$.

Infrared (IR) spectroscopy is commonly used to detect and quantify the hydroxyl contents in nominally anhydrous minerals. In all these studies the tacit and probably erroneous assumption is made that hydroxyl anions represent the end stage of the dissolution mechanism of $\mathrm{H}_{2} \mathrm{O}$.

Studying the dissolution of $\mathrm{H}_{2} \mathrm{O}$ in $\mathrm{MgO}$ as a structurally simple model oxide, a peculiar reaction was discovered, which seems to have broad significance in the mineral world. When $\mathrm{H}_{2} \mathrm{O}$ becomes incorporated into $\mathrm{MgO}$ at high temperatures during crystallization from an $\mathrm{H}_{2} \mathrm{O}$ - laden melt, hydroxyl anions, $\mathrm{OH}^{-}$, are formed alongside with $\mathrm{Mg}^{2+}$ vacancies. In a reaction, which takes place during cooling through the $600-400^{\circ} \mathrm{C}$ range, $\mathrm{OH}^{-}$pairs at $\mathrm{Mg}^{2+}$ vacancy sites rearrange electronically: the two hydroxyl $\mathrm{O}^{2-}$ transfer an electron each to their respective protons, $\mathrm{H}^{+}$, thereby forming an $\mathrm{H}_{2}$ molecule, while the $\mathrm{O}^{2-}$ anions change from the -2 to the -1 oxidation state. The $\mathrm{O}^{-}$combine to form a peroxy anion, $\mathrm{O}_{2}{ }^{2-}$, marked by a very short but also quite labile $\mathrm{O}^{-}-\mathrm{O}^{-}$bond. A peroxy anion is a PHP as defined above, i.e., an electrically inactive, dormant pair of p-holes, waiting to be "awoken" (Freund et al. 1993). Later studies summarized in (Freund 2003) provided evidence that this redox reaction, in which some oxygen anions change their valency from 2- to 1-, is not limited to $\mathrm{MgO}$ but of widespread occurrence also in a range of silicate minerals, where it can be written more generally as: $\mathrm{O}_{3} \mathrm{X}^{\mathrm{OH}}{ }_{\mathrm{HO}} / \mathrm{XO}_{3} \Rightarrow \mathrm{O}_{3} \mathrm{X} /{ }^{\mathrm{OO}} \backslash \mathrm{XO}_{3}+\mathrm{H}_{2}$.

The presence of molecular $\mathrm{H}_{2}$ as predicted by this in situ redox reaction has been confirmed in a number of igneous and high-grade metamorphic rocks (Freund et al. 2002a). 
Therefore, we can presume that these crustal rocks, which have all crystallized or recrystallized in $\mathrm{H}_{2} \mathrm{O}$ - laden magmas or other $\mathrm{H}_{2} \mathrm{O}$ - laden environments, also contain PHPs.

Here we show through a series of laboratory experiments that (i) p-hole charge carriers can be activated by mechanical stress, presumably from the dormant, yet labile PHP precursors, (ii) the p-hole activation leads to an increase in the electrical conductivity, and (iii) the electrical conductivity increases not only within the stressed rock volume but also in the surrounding unstressed rocks.

Recognizing the presence of p-hole charge carriers in rocks may have far-reaching implications for understanding those non-seismic pre-earthquake signals like low frequency EM emissions and local magnetic field anomalies, which require powerful electrical currents in the ground.

\section{EXPERIMENTAL}

We report on a series of experiments carried out between June 2003 and April 2004 as a first attempt to study the changes in electrical conductivity induced by stress. We used two igneous rocks, a quartz-bearing granite and a quartz-free anorthosite. The granite was available in the form of slabs of different size and thickness with unfinished, saw-cut surfaces. The anorthosite was available in the form of $30 \times 30 \mathrm{~cm}^{2}$ tiles, $9.5 \mathrm{~mm}$ thick. One surface of the tiles was polished while all other surfaces were left as cut with the diamond saw. All samples were air-dry. As reference material, which is not expected to contain PHPs and p-holes, we used commercial Na-Ca-Al-silicate plate glass with the same dimension as the rock tiles.

The granite is a medium-grained grayish-white granite from the Sierra Nevada batholith, available under the trade name Sierra White. It comes from a quarry in Raymond, CA, has a bulk density of $2.67 \mathrm{~g} \mathrm{~cm}^{-3}$, a compressive strength of $170 \mathrm{MPa}$, a tensile strength of $13 \mathrm{MPa}$, and an average porosity of $0.31 \%$. Anorthosite is a coarse-grained lower crustal rock. Our samples come from the Lundh quarries $20 \mathrm{~km}$ west of Larvik, Norway, and are available under the trade name Blue Pearl. The main mineral component is Ca-rich feldspar (labradorite) with crystals in the $10-25 \mathrm{~mm}$ size range. The bulk density is $2.68-2.72 \mathrm{~g} \mathrm{~cm}^{-3}$, the compressive strength $180-190 \mathrm{MPa}$, the tensile strength $13 \mathrm{Mpa}$, and the porosity range $0.12-0.16 \%$.

During rock deformation and fracture experiments as described in the literature, the samples are usually loaded over their entire cross sections (Yoshida et al. 1998; Takeuchi and Nagahama 2001). Our approach in the present paper is different. We are using rock samples that are larger than the pistons. In this manner we place only a small sub-volume of the sample under compressive stress keeping the surrounding rock largely stress-free or under the effect of relatively weak compressive and tensile stresses. To confine the pressure and achieve higher loads before failure, the glass and anorthosite tiles were mounted in a metal frame, made of $2.5 \times 2.5 \mathrm{~cm}^{2}$ aluminum stock, as depicted in Fig. 2, while the granite slabs were used as such, without confinement in the frame.

The rocks were loaded uniaxially between two pistons, using a SATEC hydraulic press, Model Prism 500 QC. The load rate, which had to be adjusted manually, varied from 1-5 MPa/min. Sometimes, especially when making first contact, the rock samples were inadvertently 


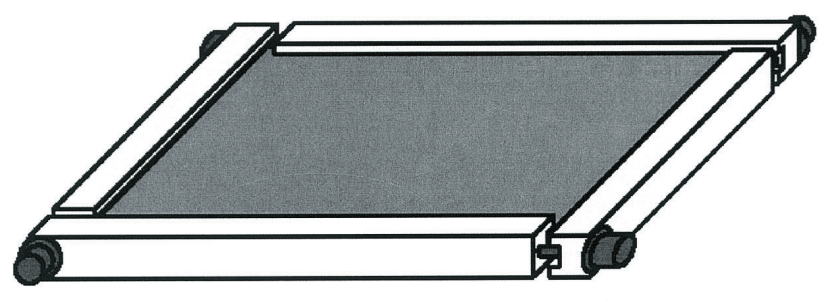

Fig. 2. Metal frame used to confine the rock tiles during the uniaxial loading experiments.

subjected to a relatively high load, up to $1-2 \mathrm{MPa}$, at the beginning of a run. As pistons we used either steel cylinders, $7.3 \mathrm{~cm}$ diameter or rectangular steel bars, $4 \times 22 \mathrm{~cm}^{2}$ with beveled rims to minimize the stress gradients along the edges. The pistons were electrically isolated from ground by $0.8 \mathrm{~mm}$ thick sheets of dense polyethylene with a resistance of $>10^{14} \Omega$. In most of the cases reported here, we used the pistons as electrodes, applying a dc voltage across them, typically $+100 \mathrm{~V}$, to measure the current that can flow through the stressed rock volume. In other cases we biased both pistons at $\pm 100 \mathrm{~V}$ and measured the current that can flow from the stressed rock volume, the "source volume", through the essentially unstressed rock to ground. Lastly, to measure (i) self-generated potentials between the source volume and ground and (ii) currents flowing into or out of the stressed rock volume, we left the pistons unbiased. In all cases, to assure good electrical contact, we used conductive $\mathrm{Cu}$ tape between the pistons and the rocks. To measure the currents we used Keithley 486 and 487 picoampmeters. To measure the voltages we used a Keithley 617 electrometer. For recording rapid processes we used a $200 \mathrm{MHz}$ Tektronix 4 - channel oscilloscope, model TDS4020. Additional details on the experimental procedure will be given in the sections below.

\section{RESULTS}

\subsection{Glass}

We used the metal frame as depicted in Fig. 3a. We loaded the glass tiles in the center. A typical fracture pattern is seen in Fig. 3b. First, during run \#52, we applied $+100 \mathrm{~V}$ to both pistons and measured the current flowing from the pistons to the ground metal frame as shown in the inset in Fig. 3c. With the voltage applied the current is in the order to $80 \mathrm{fAmp}$ range ( 1 femtoAmp $=10^{-15} \mathrm{Amp}$ ), at the limit of what the Keithley 486 can reliably measure. Upon loading the current does not increase but stays between 70 - 90 fAmp until the glass title begins to fracture. At that time short current pulses are recorded with an amplitude of \pm 20 fAmp. Second, during run \#53, we applied 100V across the two pistons measuring both the piston-to-piston current through the $9.5 \mathrm{~mm}$ thick glass title and the current from the pistons to the grounded frame as shown in Fig. 3d. Both currents are in pAmp range so long as no 
(a)

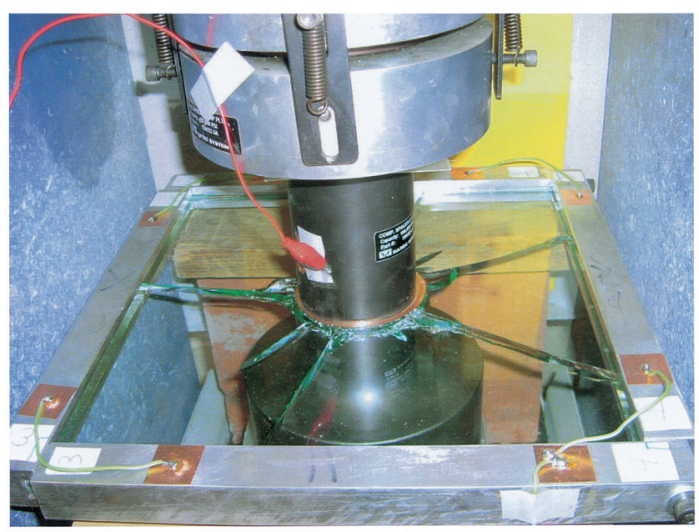

(b)

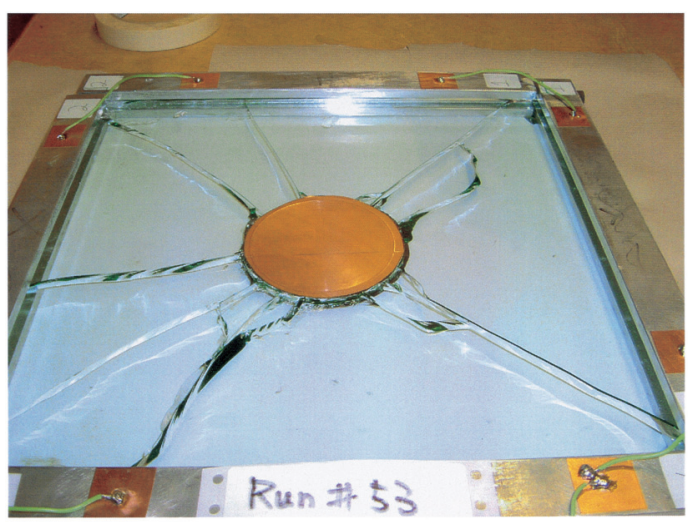

(c)

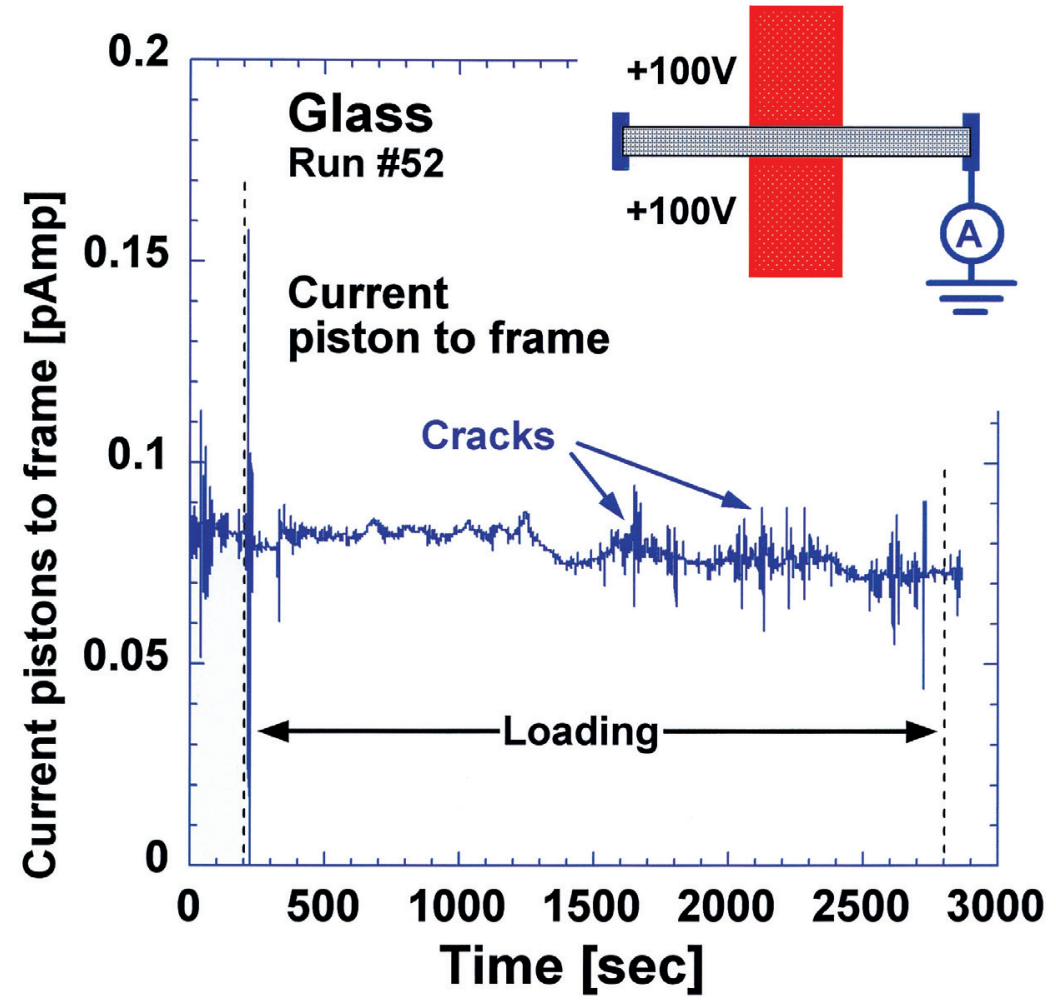




\section{(d)}

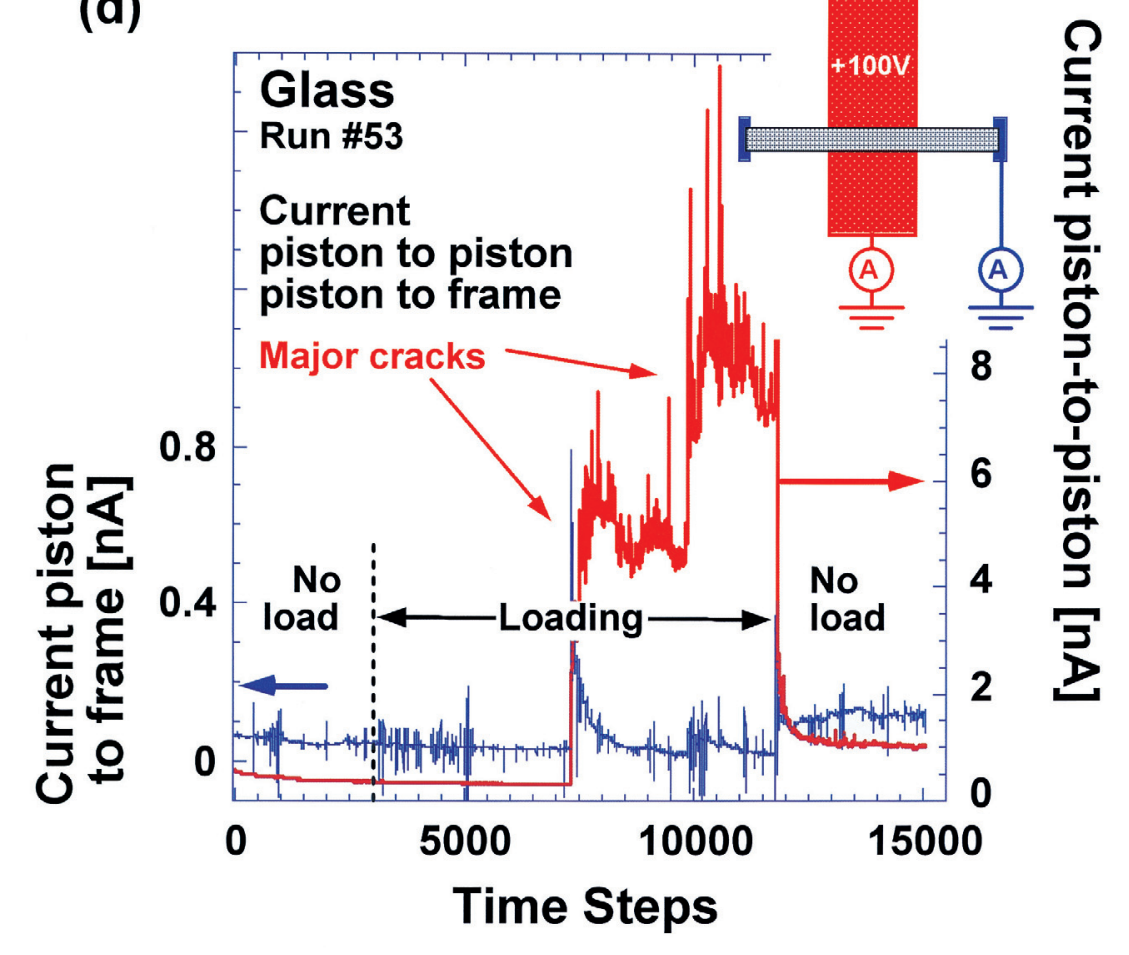

Fig. 3. (a) Glass tile mounted in the metal frame in the SATEC press at the end of a run. Both pistons can be seen with some of the electrical contacts; (b) Glass tile after the run with a typical fracture pattern and the contact electrodes made with electrically conductive $\mathrm{Cu}$ tape; (c) There is a current of $0.075 \mathrm{pAmp}$ between the central pistons, biased at $+100 \mathrm{~V}$, and the grounded metal frame but essentially no change during loading up to fracture except for spikes in the order of \pm 20 fAmp during crack formation; (d) Experiment with $100 \mathrm{~V}$ applied across the pistons. Current through the $9.5 \mathrm{~mm}$ thick glass tile under stress (red) and current to the metal frame (blue).

cracking occurs ${ }^{6}$. At the moment of major cracking the piston-to-piston current rises to the 510 nAmp range $\left(5 \times 10^{-9}-10^{-8} \mathrm{Amp}\right)$, while the piston-to-frame current remains low with a short bursts during cracking.

\footnotetext{
${ }^{6}$ At very low current levels and with highly insulating materials, a shift in the baseline often occurs in either positive or negative direction, which is generally caused by depolarization currents due to electrostatic charging.
} 
The main conclusion to be drawn from these two experiments with the glass tiles is (i), the conductivity through the essentially unstressed glass volume, i.e. the current flowing from the stressed volume between the pistons to the grounded metal frame, is very low and does not react to the application of stress, and (ii) the conductivity through the stressed glass volume between the pistons does not increase with the application of stress but only when fractures occur that open new surfaces and new current pathways.

\subsection{Granite}

The situation changes quite markedly when we place thin slabs or tiles of igneous rocks under similar levels of uniaxial stress. We first describe an experiment with a rectangular slice of Sierra White granite, $8 \mathrm{~mm}$ thick and larger than the piston diameter as shown in the insert in Fig. 4a. The rock was not confined in a metal frame. It was loaded at an approximately linear rate of $5.6 \mathrm{MPa} / \mathrm{min}$ over the run time of $30 \mathrm{~min}$. Before and during loading we applied dc voltages from $0 \mathrm{~V}$ to $+1000 \mathrm{~V}$ in $+100 \mathrm{~V}$ increments for $30 \mathrm{sec}$ at each step. For graphical representation the data are divided into six time windows as shown in Fig. 4a labeled $0 \mathrm{~V}$ to $1000 \mathrm{~V}$.

The response was ohmic, suggesting that the currents are not limited by charge carrier injection at the electrodes. Fig. $4 \mathrm{~b}$ shows the current versus voltage plots in these six time windows. In Fig. $4 \mathrm{c}$ we plot the conductivity as a function of time. At zero load, the value is $0.7 \times 10^{-9} \mathrm{Sm}^{-1}$. The conductivity increases quickly by a factor of 4 after the start of loading and continues to increase slightly at higher stress levels. Such a stress-induced increase in the conductivity through the stressed rock volume is very different from the behavior of the glass.

This observation led to the next question: Does the conductivity increase occur only in the stressed rock volume between the pistons or is there also a noticeable conductivity increase in the area outside the pistons, where the rock is nominally unstressed?

For this purpose we took an irregular slab of granite, larger than the piston diameter and $13 \mathrm{~mm}$ thick, and loaded it as shown in Fig. 5a. The pistons served as one set of electrodes. In addition we placed a second set of electrodes outside the pistons as shown by the inserts in Fig. $5 \mathrm{a}$. The dc voltage applied cross the pistons and across the second pair of electrodes was the same, $100 \mathrm{~V}$.

The results are shown in Fig. 5b. At the beginning of the run, the currents flowing between the pistons and to the outside electrodes were of the order of $2 \mu \mathrm{Amp}$ and $0.1 \mu \mathrm{Amp}$, respectively ${ }^{7}$. Upon loading the current between the pistons increased in an almost stepwise manner to $5 \mu \mathrm{Amp}$ and then continued to rise to about $63 \mu \mathrm{Amp}$ at the moment of failure. Failure of this unconstrained granite sample occurred at about $65 \mathrm{MPa}$. The current flowing between the outside set of electrodes also increased sharply after application of the load to 0.8 $\mu \mathrm{Amp}$, then began to fluctuate strongly. The fluctuations seem to correlate with steps in the current between the pistons, i.e., with the current through the stressed rock. Halfway through

7 The higher initial current flowing from piston to piston was caused by an overshoot during the loading phase when the pistons made contact with the sample and the stress briefly reached 1-2 MPa. 

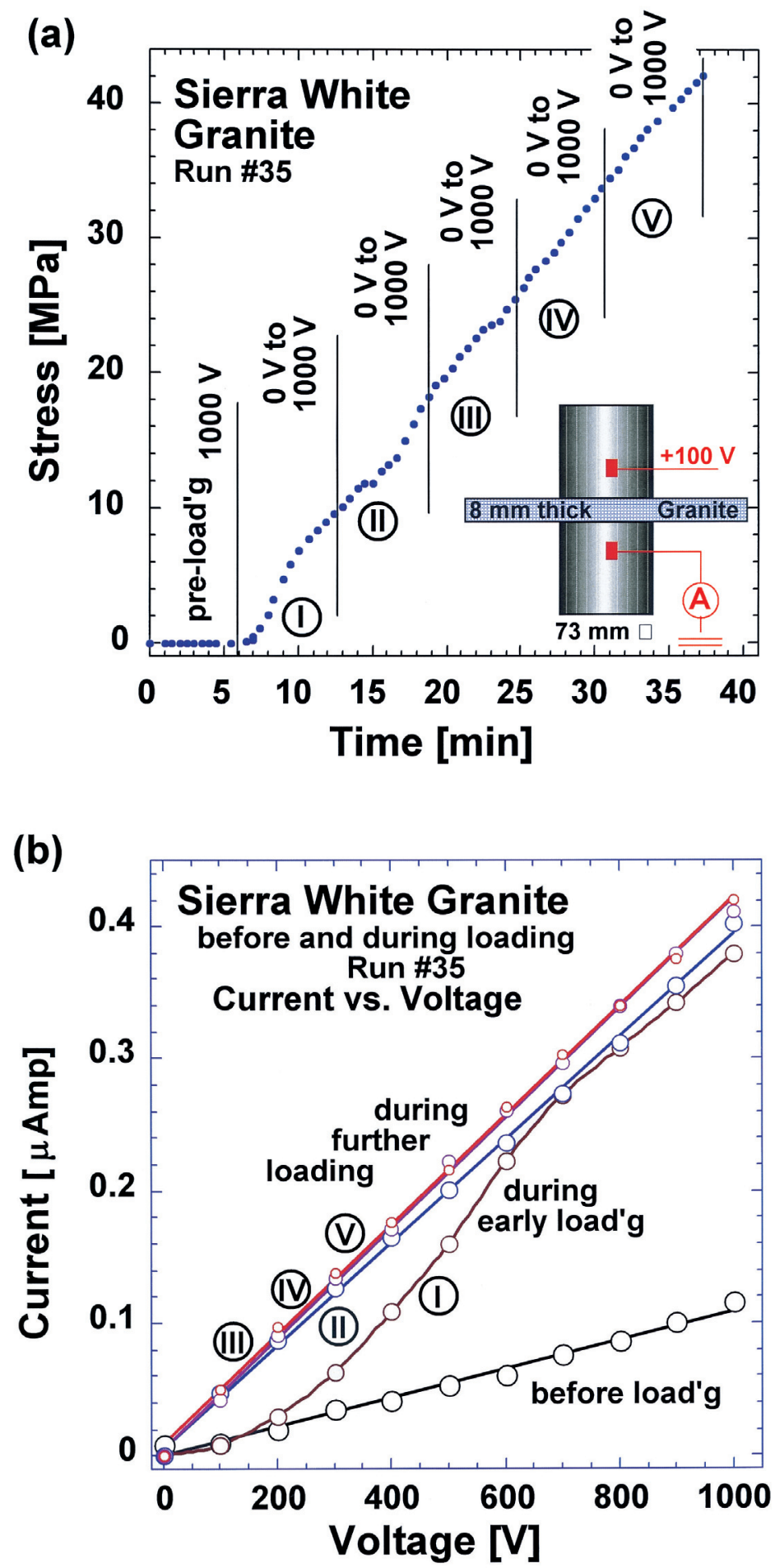


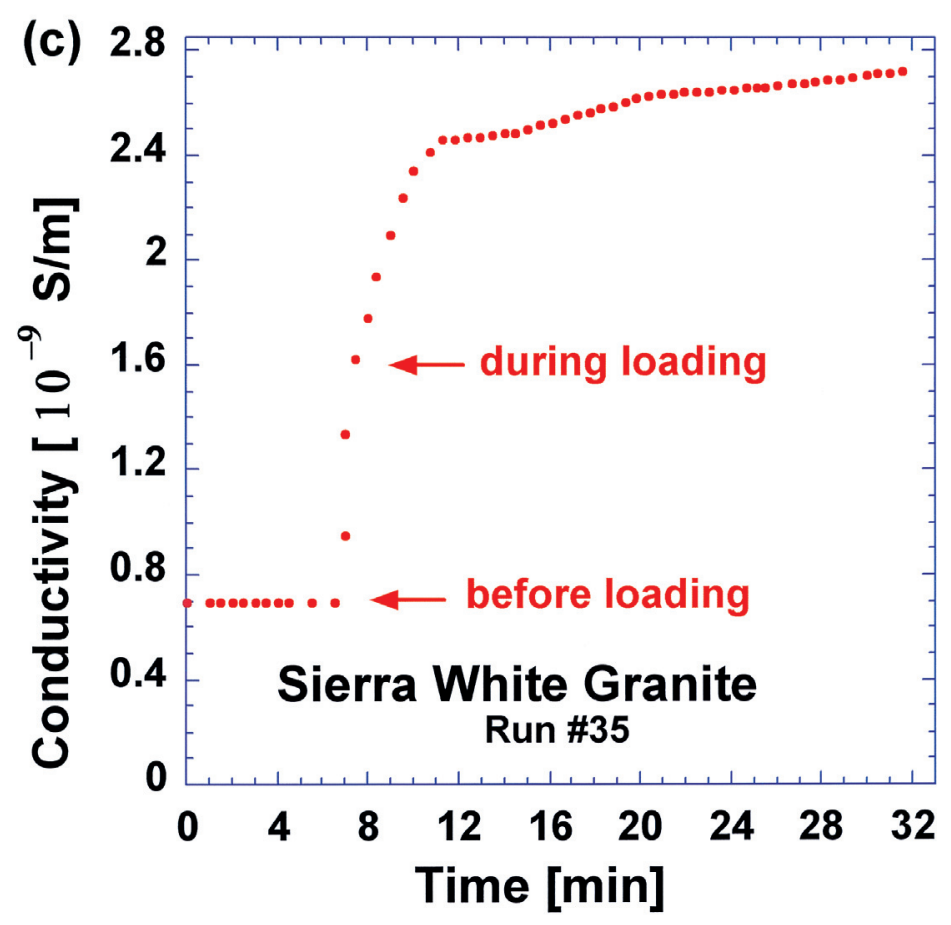

Fig. 4. (a) Stress versus time plot for a conductivity experiment using a slab of granite and the pistons as electrodes as shown in the insert. The six time windows indicate when the voltages were increased in $100 \mathrm{~V}$ steps from 0 to $1000 \mathrm{~V}$; (b) Linear response suggesting ohmic behavior except in the time window (I) where the conductivity changes rapidly as the load is first applied giving a curved response; (c) Conductivity versus time of the granite slab showing a baseline conductivity of the unloaded granite, which increases upon loading.

the run, however, the current between the outer electrodes had decreased to values close to those before loading.

The rapid, almost stepwise initial increase in the current, while the load was still low, is a feature that we have often observed. It suggests that low levels of stress suffice to activate charge carriers in the affected rock volume. Thereafter, as the stress on the rock increases, the current between the pistons increases too. However, there is also an increase in the current between the outer electrodes, i.e., outside the area of the highly stressed rock volume between the pistons. The increase in the latter current could be either due to weak stresses transmitted from the rock between the pistons to the surrounding rock, causing independent activation of charge carriers in the surrounding rock, or it could be due to charge carriers that are activated in the stressed rock between the pistons and flow out into the surrounding unstressed rock. 

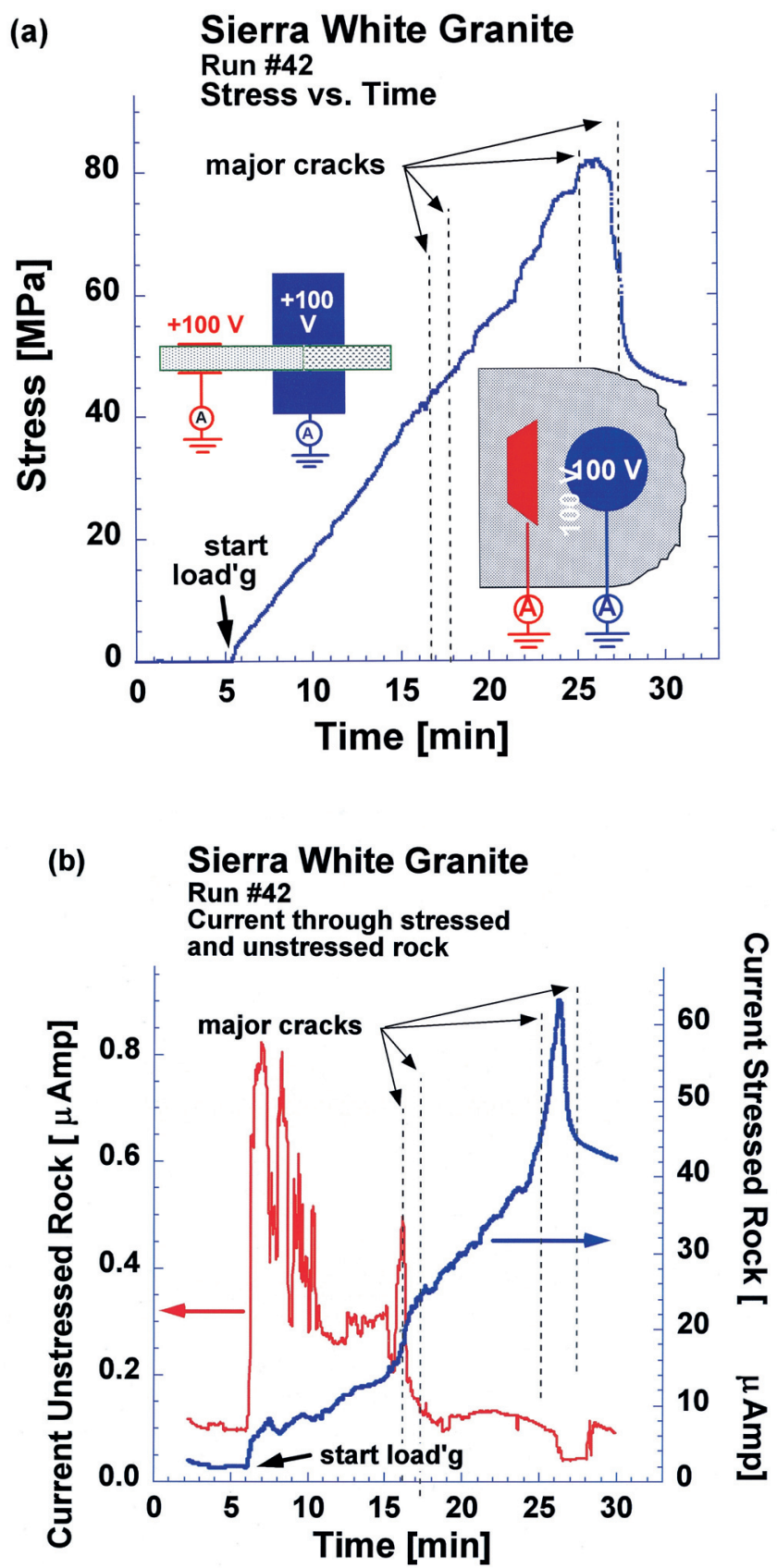

Fig. 5. (a) Stress versus time and electrode configuration for a $13 \mathrm{~mm}$ thick granite slab. (b) Stress-induced current between the pistons (blue) and between the outer two electrode contacts (red). 
We can differentiate between these two cases on the basis of how the currents evolve with time and load. If stresses transmitted from the loaded portion between the pistons to the immediate surrounding, due to Poisson's ratio (Christensen 1996), were the controlling factor, we would expect to see a continuous increase of the current between the outer electrodes throughout the run, i.e., so long as applied stress between the pistons is increasing. However, as Fig. $5 \mathrm{~b}$ demonstrates, the current through the nominally unstressed rock outside the pistons increases only during the early part of the loading curve and then decreases with strong fluctuations. This observation is inconsistent with weak stresses transmitted from the rock volume between the pistons and the idea that such stresses would control the conductivity of the surrounding unstressed rock.

Instead we have to consider an alternative case, namely that charge carriers activated between the pistons flow out of the stressed "source volume" and increase the conductivity of the surrounding rock. As to the reason why the current between the outer electrodes decreases we also have to consider microcracks, which might block the current flow. The next experiments are designed to validate whether the idea of an outflow of charge carriers from the "source volume" can be confirmed.

\subsection{Anorthosite}

We simplified the geometry of the experimental set-up, using one of the $30 \times 30 \times 0.95 \mathrm{~cm}^{3}$ anorthosite tiles, confined in the metal frame to prevent early failure due to the low tensile strength of these rocks. We biased both pistons at $+100 \mathrm{~V}$ relative to the ground along the periphery as depicted in Fig. 6. Under this condition, with an electric field gradient between the pistons and the frame, we would measure the current flowing to the frame, i.e., the current through the rock outside the stressed rock volume.

Upon loading the center of the tile the current increased near-instantly from 1.06 to 1.16 Amp as shown in Fig. 6. The current continued to increase through the first half of the run, reaching $1.5 \mu \mathrm{Amp}$, and then decreased as more and more cracks developed.

The currents measured through the anorthosite tile are 7 orders of magnitude larger than those measured through the glass tiles (see Fig. 3c) under identical conditions.

As evidenced by Figs. $5 \mathrm{~b}$ and 6 , we observe a sharp increase of the current flowing from the pistons to the frame already at the beginning of the run, at low loads. It is unlikely that, under these conditions, the stresses in the surrounding rock would suffice to activate the charge carriers all the way to the frame. This can be taken as an indication that another mechanism is at work that allows a current to flow from the loaded central volume to the grounded frame.

We did another test to verify that the charge carriers are positive. With the geometry of the experimental set-up depicted in Fig. 6 we expect to record a current from the source volume between the pistons to the grounded frame only when the voltage applied to the pistons is positive. The reason being that a positive voltage would "push" p-hole charge carriers out toward the grounded frame, while a negative voltage would confine them in the source volume. When we changed polarity, applying $-100 \mathrm{~V}$ to the pistons instead of $+100 \mathrm{~V}$, the current decreased near-instantly to background values in the pAmp range, confirming that the charge carriers activated in the source volume are indeed positive, hence p-holes. 
The experiment presented in Fig. 6 does not yet rule out that weak stresses transmitted laterally from the rock between the pistons may cause the observed conductivity increase in the surrounding rock. It is therefore of interest to determine how the stresses decay from the pistons toward the periphery of the rock tile.

Figure 7 shows a finite element analysis of the stress distribution in the tile. The analysis applies to static stress applied to a perfectly elastic material within the range of Hooke's law, i.e., linear elastic response. Ten stress levels are color-coded in (Fig. 7a) for the range 0 to $100 \%$ and in (Fig. 7 b) for the range 0 to $10 \%^{8}$. In both cases the stress is uniform over the piston area. Outside the pistons the stress decays rapidly and remains below the $10 \%$ level all the way to the edge. When we look at the $0-10 \%$ range as in (b), we see stresses up to the 5\% level spreading out to the edge with the corners remaining below the $1 \%$ level.

${ }^{8}$ In (a) $100 \%$ is set at 37,000 psi, equivalent to the compressive strength of anorthosite. In (b), because of the ideal elastic behavior, a 10 -fold higher load value is used to magnify the $0-10 \%$ range.

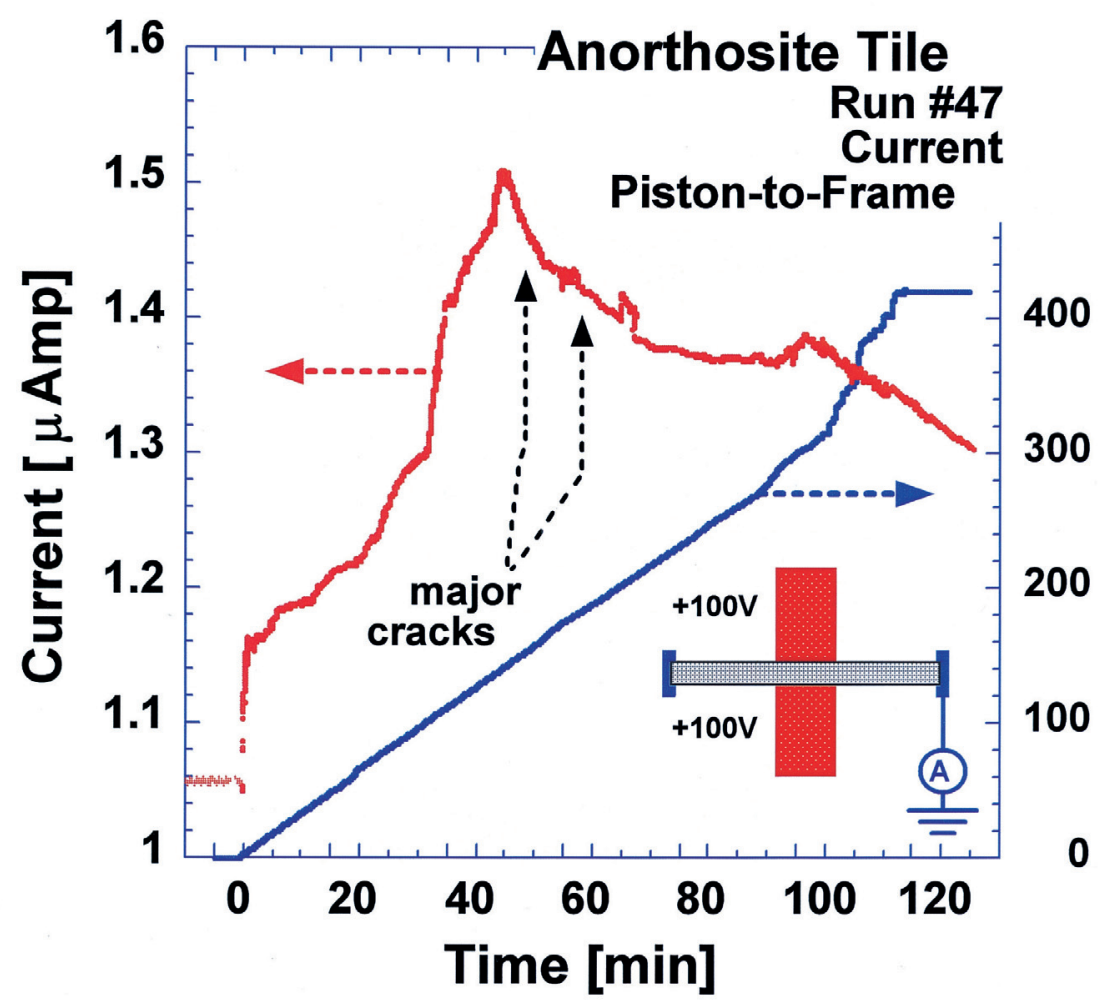

Fig. 6. Current (red) and stress (blue) versus time and electrode configuration where both pistons are biased at $+100 \mathrm{~V}$ relative to the ground around the periphery of the anorthosite tile. Note the rapid increase in the current flowing to ground at the beginning of loading. 
(a)

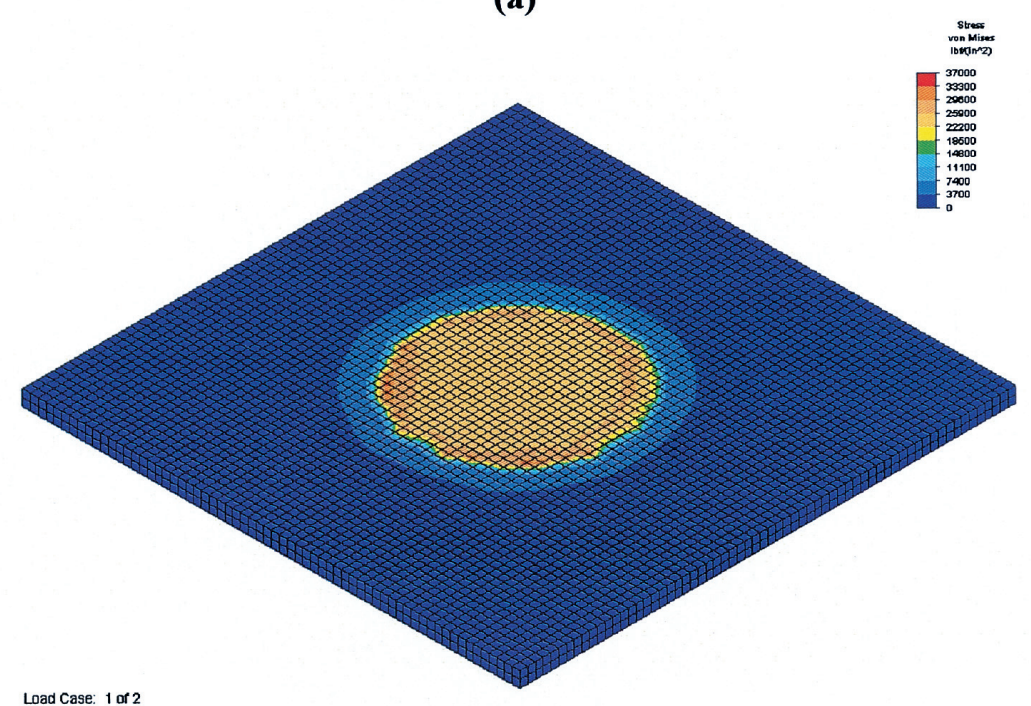

Load Case: 1 of 2

Maximum Value: 36954.6 1bf(inn 2$)$

Mininum Value: $3.24721 \mathrm{lbl} /\left(\mathrm{ln}^{\mathrm{n}} 2\right)$

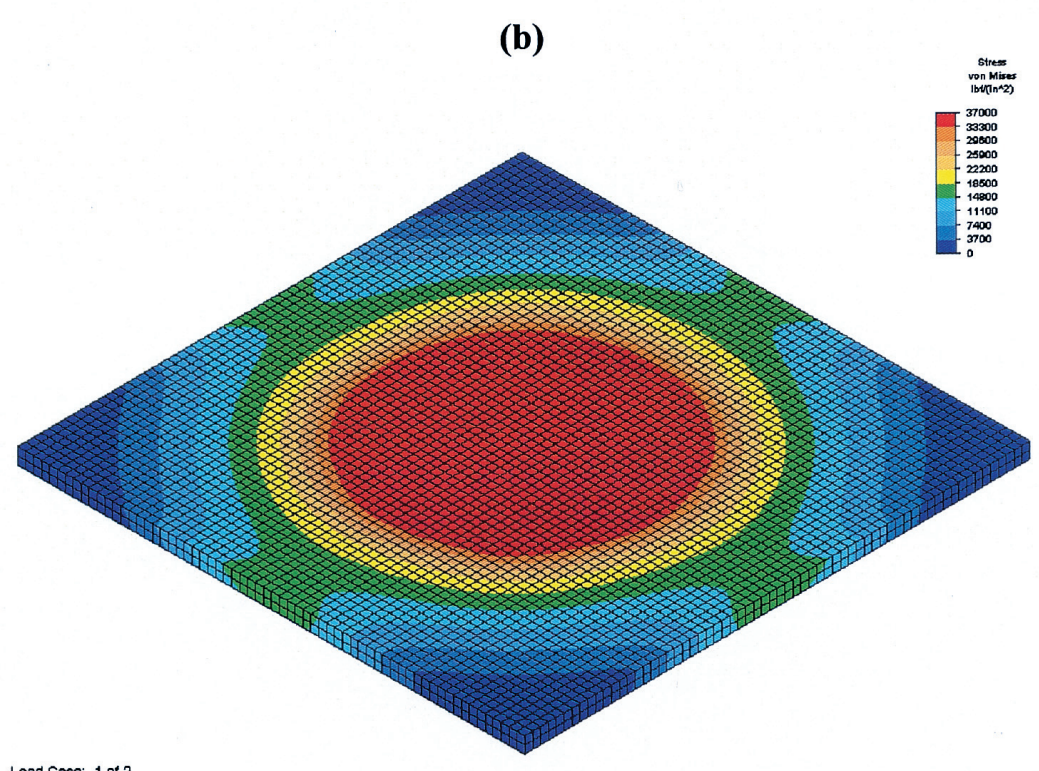

Load Case: 1 of 2

Maxdmum Value: 369546 Ibt/(In'2)

Minimum Value: 32.4721 lott(inn2)

Fig. 7. (a,b) Finite element analysis of the stress distribution in the anorthosite tile representing the $0-100 \%$ range (top) and $0-10 \%$ range (bottom). 
We can use these calculated stress distributions to address the question why the current flowing from the pistons to the frame in Fig. 6 and the current between the outer electrodes in Fig. $5 \mathrm{~b}$ rose so sharply at the beginning of the load application. There are two possible explanations: (i) while low levels of stress suffice to activate the charge carriers within the volume of rock between the pistons, even lower levels of stress, in the order of $<5 \%$, activate the same charge carriers in the outlying regions of the tile, or (ii) charge carriers activated within the volume of rock between the pistons, the source volume, are capable of spreading out into essentially unstressed or very weakly stressed rock and even reach the edge of the tile.

Case (i) could possibly explain the initial sharp rise of the current but is inconsistent with the observation that the currents tend to decrease later in the runs as demonstrated in Fig. $5 \mathrm{~b}$ and Fig. 6. If low levels of stress were enough to activate the charge carriers, one would expect a continuous increase of the current to the frame similar to the current between the pistons (see Fig. 5b). This is not observed.

With the electrode configuration depicted in Fig. 6 we cannot determine how much current flows along the surfaces of the tile. We modified the set-up as depicted in Fig. 8a by adding a set of square guard electrodes, made of a $6.3 \mathrm{~mm}$ wide $\mathrm{Cu}$ strip, on both sides of the tile halfway between the pistons and the frame to capture any surface currents. Any current flowing past the guard electrodes would have to be a bulk current. Therefore, every $30 \mathrm{sec}$, the guard electrodes were connected for $30 \mathrm{sec}$ to the picoampmeter and then disconnected, i.e., left floating, for $30 \mathrm{sec}$. During all this time we measured the current flowing from the pistons to the guard electrodes, when connected, and the current flowing past the guard electrodes to the frame.

The results are shown in Fig. 8b. Before application of the load, with the guard electrodes disconnected and floating, the current between the $+100 \mathrm{~V}$ pistons and the frame was in the order of $0.2 \mu \mathrm{Amp}$. When the guard electrodes were grounded, they captured $0.7 \mu \mathrm{Amp}$, but a small current, of the order of $0.1 \mu \mathrm{Amp}$, continued to reach the outer frame. Upon loading, all three currents increase, reaching maxima early around $0.8,1.9$, and $0.5 \mu \mathrm{Amp}$, respectively, and slightly lower values during the rest of the run, up to the time of failure.

The increase of the currents upon loading confirms the findings of the two earlier experiments shown in Figs. 5b and 6. The fact that the frame continues to draw currents even when the guard electrodes are connected to ground confirms that a current flows through the interior of the tile, i.e., through the bulk of the rock. The ratio of the current reaching the outer frame with the guard connected to the current reaching the outer frame with the guard electrodes floating is constant throughout the run.

In all cases presented so far we imposed an electric field, either vertically across the source volume or laterally between the pistons and ground, i.e., across the rock outside the pistons. Under these conditions we observe that, when load is applied, the currents increase both vertically between the pistons and laterally between the pistons and ground. The currents seem to always increase rapidly, in an almost stepwise fashion, as soon as the load is applied as Figs. 5b, 6 and $8 \mathrm{~b}$ demonstrate. This suggests that the relatively low levels of stress acting on the rock between the pistons suffice to activate the charge carriers. During further loading the currents continue to increase, generally reaching a maximum at about half the failure load, and then decay. 
(a)

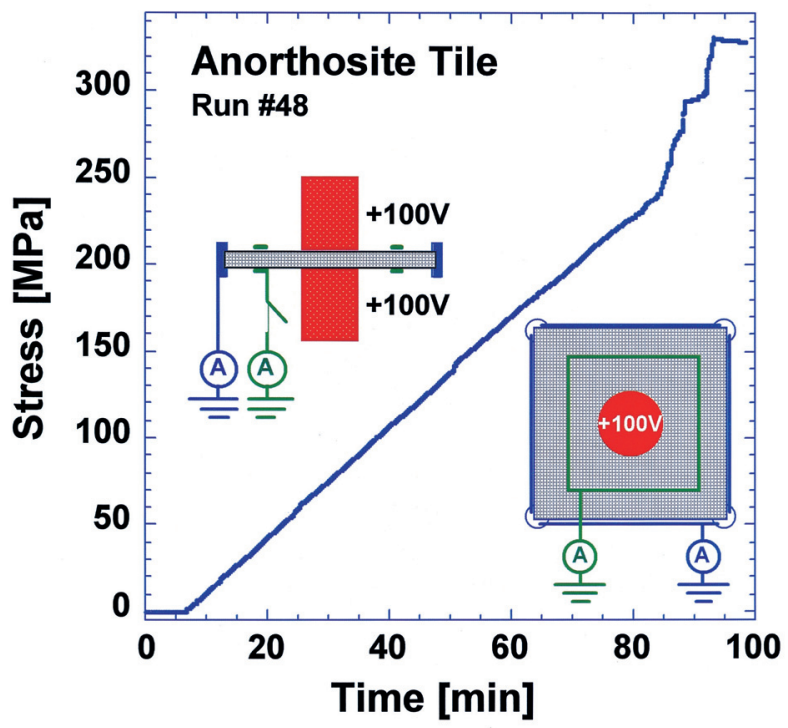

(b)

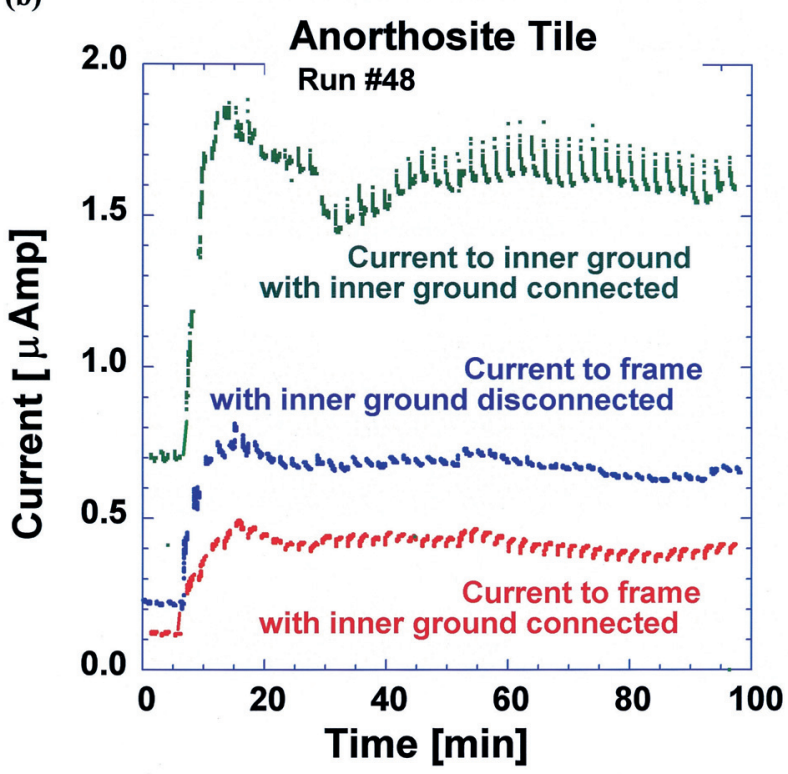

Fig. 8. (a) Load versus time plot and electrode configuration used to discriminate between surface and bulk currents; (b) Currents flowing outward from the stressed rock volume between the pistons, which are both biased at $+100 \mathrm{~V}$ relative to ground, and in part captured by the set of grounded guard electrodes halfway between the pistons and the grounded frame. 
A limitation of all these experiments is that, in order to measure a current, we always imposed an electric field. However, if the rock volume between the pistons acts as the source volume from where p-holes flow out into the surrounding rock, we expect to see a self-generated electric potential across the rock, due to the lateral movement of charges.

We set up an experiment to measure (i) the potential difference between the pistons and a capacitor plate on the rock surface, and (ii) the current flowing to ground. Instead of round pistons acting on the center of the tile we used a pair of rectangular pistons with an area of $22 \times 3.8 \mathrm{~cm}^{2}$. We placed both pistons in electrical contact with the tile but insulated them from the press by means of $0.8 \mathrm{~mm}$ of plastic. Thus, we allowed charges, which the stressed rock would generate, to flow into the steel pistons. We insulated three edges of the tile from the frame but applied a $\mathrm{Cu}$ stripe to one edge as the ground contact. We measured (i) the voltage between the pistons and the capacitive sensor using the Keithley 617 electrometer, and (ii) the current flowing to the ground using the Keithley 486 picoampmeter.

As soon as we began loading we observed a potential difference that developed between the pistons and the capacitor as shown in Fig. 9. Since anorthosite does not contain quartz, the observed voltage cannot be due to a stress-induced piezoelectric potential. The surface potential is positive, indicating that the charge carriers are positive. At the same time as the surface potential is building up, a current is flowing from the volume between the pistons to the electrode over $20 \mathrm{~cm}$ away. Even after the load was put on constant, 50 min into the run at about $81 \mathrm{MPa}$, the surface potential continued to become more positive for another $10-15 \mathrm{~min}$. The current also continued to increase for about $10 \mathrm{~min}$, reaching $40 \mathrm{pAmp}$ before decaying slowly.

Table 1 lists essential parameters included in this first set of experiments with rocks and glass.

\subsection{Relation between Voltage Pulse and Fracture}

Lastly, we report on an experiment designed to measure at what time during loading the p-hole charge clouds are generated relative to the moment of fracture. Valianatos and Tsanis (1998) have shown that preseismic and coseismic electrical signals are related to the rate with which the rocks are deformed. During stick-slip experiments with granite cylinders, Takeuchi and Nagahama (2001) observed a sharp voltage pulse arriving 1-2 msec before the actual slip as manifested by the arrival of the acoustic signal. In their case the voltage pulses were mostly positive, followed by a broader negative voltage signal, but negative pulses were also observed.

For our uniaxial rock deformation experiment we set up a thick slab of granite between two sheets of the high-insulation plastic, equipped with a microphone about $1 \mathrm{~cm}$ from the pistons and a capacitive sensor with an area of $4 \times 5 \mathrm{~cm}^{2}$ about $10 \mathrm{~cm}$ from the pistons. The acoustic signals from major cracks that occurred during loading were used to trigger the data acquisition system of the Tektronix TDS40204-channel oscilloscope to record the acoustic signals arriving at the microphone and the voltages recorded by the capacitive sensor. We recorded 12 events. Figure 10 shows a typical result: a sharp positive voltage reaching almost $+3 \mathrm{~V}$ that arrived about $1.5 \mathrm{msec}$ before the acoustic signal. The initial voltage pulse was always positive and followed by a broader negative voltage signal, reaching about $-0.8 \mathrm{~V}$ before returning to the baseline. 


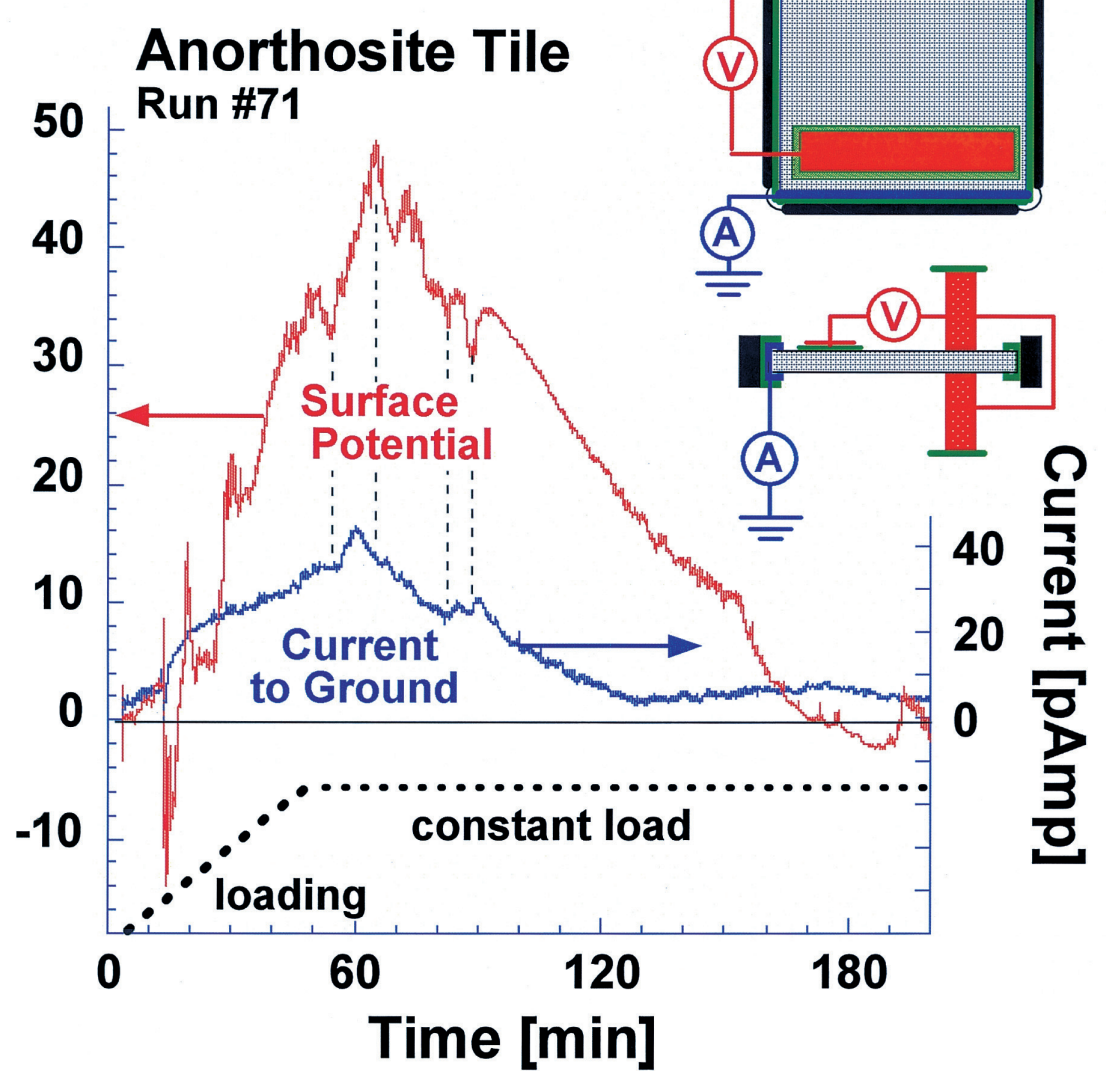

Fig. 9. Self-generated electric field between the pistons, which are in electrical contact with the rock, and the capacitor, plus the self-generated currents from to ground; Surface potential (red) and current (blue) flowing into and out of the rock from ground. The loading rate was linear up to $50 \mathrm{~min}$ into the run. Thereafter the load was kept constant at $81 \mathrm{MPa}$. The dashed vertical line points to the change from linear loading to constant load.

The sample under study here is quartz-bearing granite, which could, in principle, produce a piezoelectric voltage signal, when placed under stress. However, no voltage signal has been observed that would scale with the applied stress. Instead, we see a time-dependent behavior, where a distinct, positive voltage pulse always seem to precede the fracture. The time sequence between the voltage pulse arriving first and the acoustic signal arriving later suggests that a cloud of positive charges is generated just before the stresses in the rock reach the critical level at which fracture occurs. 
Table 1. Overview of samples and conditions.

\begin{tabular}{|l|l|l|l|}
\hline Experiment / Samples & Sierra White Granite & Blue Pearl Anorthosite & Glass \\
\hline $\begin{array}{l}\text { Current through stressed } \\
\text { rock volume with externally } \\
\text { applied electric field }\end{array}$ & $\begin{array}{l}\# 35: 0-1000 \mathrm{~V} \\
\# 42: 100 \mathrm{~V} \text { on pistons }\end{array}$ & $\begin{array}{l}\# 53: 100 \mathrm{~V} \\
\text { across pistons }\end{array}$ \\
$\begin{array}{l}\text { Current through unstressed } \\
\text { rock volume with externally } \\
\text { applied electric field }\end{array}$ & $\begin{array}{l}\# 42: 100 \mathrm{~V} \text { on pistons } \\
\text { and on a set of outside } \\
\text { electrodes }\end{array}$ & $\begin{array}{l}\# 47:+100 \mathrm{~V} \text { on } \\
\text { both pistons, } \\
\text { frame at ground. } \\
\# 48+100 \mathrm{~V} \text { piston }\end{array}$ & $\begin{array}{l}\# 52+100 \mathrm{~V} \text { on } \\
\text { both pistons, } \\
\text { frame at } \\
\text { ground. }\end{array}$ \\
\hline $\begin{array}{l}\text { Self-generated current and } \\
\text { potential without externally } \\
\text { applied electric field }\end{array}$ & $\begin{array}{l}\# 71 \text { current and } \\
\text { surface potential }\end{array}$ & \\
\hline
\end{tabular}

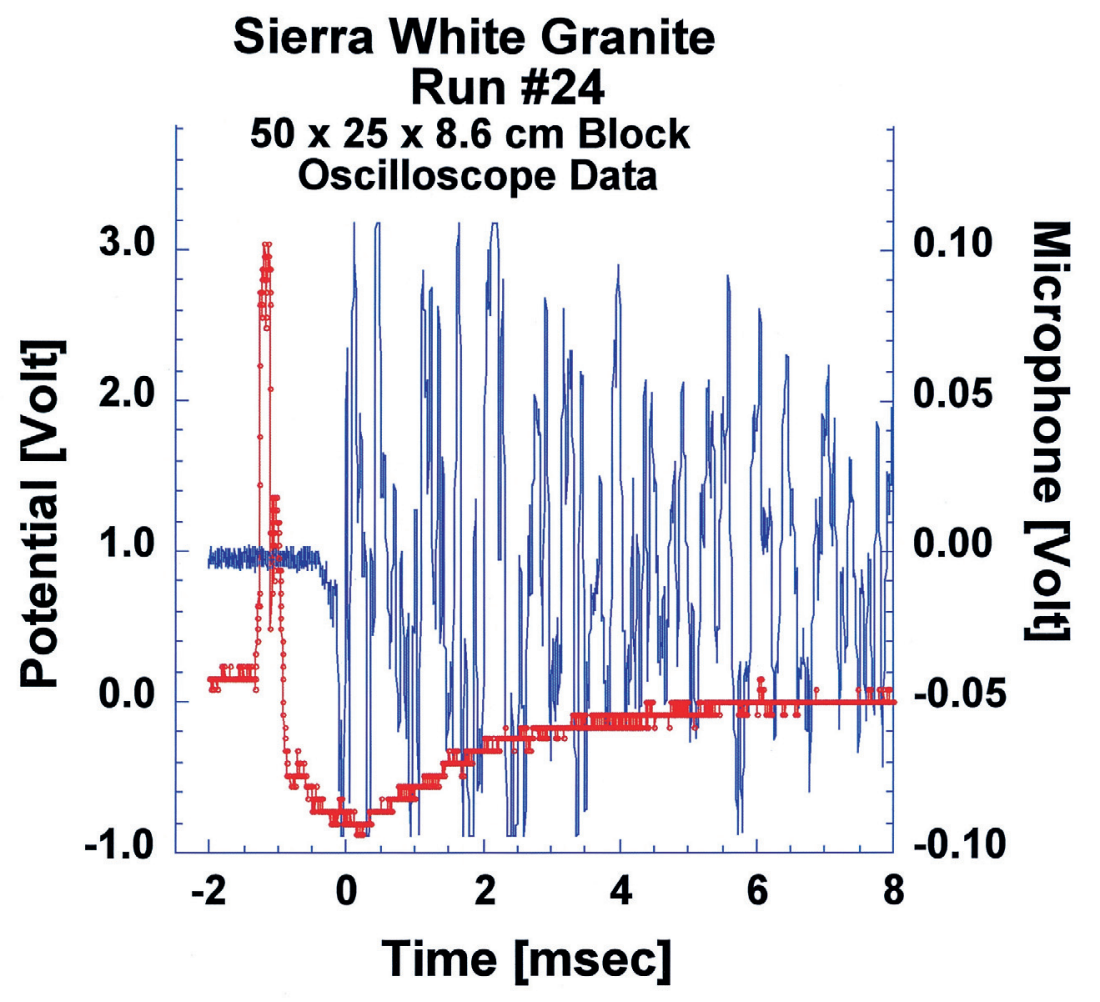

Fig. 10. During cracking the capacitive sensor registers a sharp positive voltage pulse (red), followed by a broader negative signal, before the microphone registers the acoustic signal (blue) indicating that the crack had occurred. 
Such a response would be expected, if a mechanism exists, by which positive charge carriers are generated in large numbers shortly before fracture. It is consistent with p-hole charge carriers being activated by dislocations, which are formed in very large and ever increasing number as the rock is stressed and approaches catastrophic failure. However, the maximum rate at which dislocations are generated is reached when the dislocations attain a critical density and begin to coalesce into microcracks. The microcracks in turn coalesce into major cracks, which initiate catastrophic failure (Miguel et al. 2001).

\section{DISCUSSION}

\subsection{General}

The experiments described here were set up to study how the electrical conductivity of rocks changes when stress is applied. Though we have not yet had the opportunity to systematically vary many important parameters, nor to include water-saturated rocks, the results obtained so far provide evidence that crustal igneous rocks such as granite and anorthosite contain dormant charge carriers, which are absent from regular alumosilicate glass. These charge carriers can be activated by stress. They are electronic in nature and positive. Hence, they are defect electrons. From earlier studies summarized in Freund (2003) we deduce that they are associated with the oxygen anion sublattice of the constituent minerals. Hence, they are "positive holes" or p-holes for short. In chemical terms a p-hole is an $\mathrm{O}^{-}$in a matrix of $\mathrm{O}^{2-}$ as explained in the Introduction. Having an unpaired spin an $\mathrm{O}^{-}$is not a stable entity. Therefore, the $\mathrm{O}^{-}$will tend to pair up with other $\mathrm{O}^{-}$to form what is to the chemist a peroxy bond, $\mathrm{O}^{-}-\mathrm{O}^{-}$, or peroxy link, $\mathrm{O}_{3} \mathrm{X} /{ }^{\mathrm{OO}} \backslash \mathrm{XO}_{3}$, with $\mathrm{X}=\mathrm{Si}^{4+}, \mathrm{Al}^{3+}$, etc.

In physical terms a peroxy bond or peroxy link represents a dormant positive hole pair, PHP. A PHP is electrically inactive but can be activated by a number of processes. The activation process of interest in the context of stress is mechanical deformation. Stresses beyond the elastic limit cause plastic deformation. The fundamental process by which solids plastically deform involves moving rows of atoms by a fraction of the unit cell parameter. This process leads to atomic dislocations, which are line defects. When many dislocations align along certain crystallographic planes, they form shear planes, which are planar defects.

Dislocations are generated in very large numbers (Hanson and Spetzler 1994), typically of the order of $10^{10}-10^{12} \mathrm{~cm}^{-2}$ (linear $\mathrm{cm}$ per $\mathrm{cm}^{3}$ ). As they move through the crystal structures, displacing rows of atoms in a zipper-like fashion, they rip apart any PHPs that lie in their path, thereby activating p-hole charge carriers. The rate of p-hole activation is expected to peak before fracture. The reason is that, as the number of dislocations and shear planes increases first in response to increasing stress, they will eventually begin to coalesce into microcracks. The microcracks will in turn coalesce into larger cracks and cascade in scale leading up to catastrophic fracture. This inferred maximum rate of dislocation movement seems to be at the root of the signal sequence seen in Fig. 10; as cracks form in the large granite block in this experiment, a positive voltage pulse is recorded milliseconds before the acoustic signal arrives. The positive voltage indicates the peak in p-hole generation. The acoustic signal indicates the 
actual crack, which occurs moments later.

The thrust of the series of experiments described here was to demonstrate that the p-hole charge carriers exist in the igneous rocks under study, that they are activated in the rock volume under stress, and that they can spread not only to the outer surface as predicted by King and Freund (1984) but also out of the source volume into the surrounding unstressed rock.

As outlined in the Introduction p-holes represent electronic states in the otherwise filled valence bands. There is evidence that the wavefunctions associated with these states are highly delocalized (Freund et al. 1994), causing the p-holes to spread over neighboring $\mathrm{O}^{2-}$ anions and to propagate through the valence band. When we apply an electric field, the p-holes carry an electric current not only through the stressed rock volume but also through unstressed rock over distances of tens of cm. Evidence for this current is seen in Figs. 5b, 6, and 8b. Even when we don't apply an electric field, the spreading of the p-hole charge carriers is seen in Fig. 9 as a current that flows out of the source volume and through the unstressed rock to the ground electrode about $20 \mathrm{~cm}$ away. The positive surface charge detected by the capacitive sensor confirms that the surrounding rock becomes positively charged relative to the source volume. When the positive potential reaches and exceeds the Schottky barrier, which is always present at any metal-to-insulator or metal-to-semiconductor contact (Sze 1981), electrons flow in from the ground, thereby closing the current loop.

Though details of the movement of charges through the rock are far from understood at the present time, recognizing that electronic charges exists in rocks and can be activated by stress can help us better understand those non-seismic pre-earthquake phenomena, which require powerful electrical currents flowing in the ground. The next sections contain ideas as to how p-hole charge carriers may be involved in some of the widely reported and often well documented pre-earthquake phenomena such as EM emission, ionospheric perturbations, ground level air ionization, and thermal anomalies, which suffer so far from a lack of understanding of the underlying physical causes.

\subsection{Electromagnetic Emissions}

Electromagnetic (EM) emissions have been observed by many groups and are widely, but not universally, thought to be associated with pre-seismic activity (Oike and Ogawa 1986; Fraser-Smith 1992; Serebryakova et al. 1992; Park et al. 1993; Yoshida et al. 1994; Parrot 1994; Merzer and Klemperer 1997; Hayakawa and Molchanov 1998; Huang and Ikeya 1998; Vershinin et al. 1999; Gershenzon and Bambakidis 2001; Troyan and Kiselev 2001). With the information presented in this paper, i.e., the stress-activation of p-hole charge carriers in rocks such as granite and anorthosite, it may be timely to revisit some of these earlier concepts and to see whether p-hole charge carriers could provide for a less problematic explanation of the EM signals observed.

In order to generate any form of EM emission mobile electrical charges have to be available. These charges have to either move in the space domain or wax and wane in the time domain. We may extrapolate the insight gained from our laboratory data to realistic geophysical situations. For instance, we may assume that, due to plate motion, a volume of rock in a seismogenic zone experiences ever increasing levels of stress. When p-holes are activated, the 
stressed rock volume will turn into a source volume from where charge carriers flow out. Such an outflow constitutes an electric current, which in turn generates an electric field that counteracts the outflow. The field will initiate other charge fluxes, for instance an influx of charges, which reduce the counteracting field. The result will be that the p-hole outflow from the source volume will wax and wane in concert with the build-up and reduction of the counteracting electric field and the charge carrier movements it engenders. To produce trains of EM signals the currents have to wax and wane repeatedly, i.e., to pulsate or oscillate. We can describe this as a system that consists of two currents in opposite directions coupled through their respective electric fields. Though details are still very sketchy, such coupled systems are known to go into oscillations (Haken 1978).

\subsection{Changes in Ground Potential and Ionospheric Perturbations}

Prior to major earthquakes the ionosphere reportedly displays remarkable perturbations (Molchanov et al. 1993; Molchanov and Hayakawa 1998b, c; Alperovich and Fedorov 1999; Chen et al. 1999; Cliverd et al. 1999; Liu et al. 2000, 2001; Pulinets et al. 2000; Sorokin et al. 2001; Pulinets and Boyarchuk 2004). These perturbations extend over large areas, of the order of $500-1000 \mathrm{~km}$, and require changes of the electric field close to ground level, which must be sufficiently strong to induce a reaction in the ionosphere.

The Earth's surface and the ionosphere can be considered as two capacitor plates. The plate at the Earth's surface is fixed, while that in the ionosphere is mobile and can adjust to changes in the electric field on the ground. Data presented by Liu et al. $(2000,2001)$ suggest that the ground potential often becomes positive prior to major earthquakes. As a result, the electron-dominated, negative plasma from the upper reaches of the ionosphere is pulled down, while the ion-dominated positive lower ionospheric layer is pushed aside. The Russian school (Sorokin et al. 2001; Pulinets and Boyarchuk 2004) proposes that a transient electric field is generated at ground level due to pre-earthquake radon emission. How the radioactive decay of radon in air should create an either positive or negative electric field is not clear.

From earlier work (Freund 2002) and the work presented here we know that p-holes activated in the source volume can spread through $10-20 \mathrm{~cm}$ unstressed rock, leading to a positive surface potential of the order of $0.4-0.5 \mathrm{~V}$. We do not know how efficiently these charge carriers spread over longer distance, including layers of water-saturated rocks. However, if pholes were to spread through kilometers of rock, they would reach the Earth's surface. There they would cause the ground potential to become positive. The center of such a ground potential anomaly is expected to lie above the source volume. Assuming a continuing supply of pholes from below, the area of abnormally high positive ground potential will expand laterally. It is conceivable that, at the center of such an anomaly, the ground could reach high positive values relative to the rim, sufficiently high to cause perturbations in the ionosphere.

\subsection{Ionization of Air, Haze Formation, Corona Discharges, and Electrostatic Noise}

One of the characteristics of p-holes is that, when they reach the surface, they become trapped form a thin positive charge layer, of the order of $10 \mathrm{~nm}$, counterbalanced by a negative 
bulk. The thickness of this charge layer and the surface potential are a function of the dielectric contrast between the dielectric and air (King and Freund 1984). For a dielectric contrast from 10 to 1 , the calculated surface potential is $0.4 \mathrm{~V}$, consistent with measured values (Freund 2002). The electric field associated with a charge layer thickness of $10 \mathrm{~nm}$ has been calculated to be in the order of $0.4 \times 10^{8} \mathrm{Vm}^{-1}$ at a flat surface (King and Freund 1984). It should be much higher at sharp points. When the density of charges reaches about $2.7 \times 10^{-5} \mathrm{Coulomb} / \mathrm{m}^{2}$, corona discharges can occur. Surface charge densities in the order of $10^{-4}-10^{-2}$ Coulomb $/ \mathrm{m}^{2}$ have been measured immediately after brittle fracture and frictional slip (Takeuchi and Nagahama 2002)

In electric fields of the order of $10^{7}-10^{8} \mathrm{~V} \mathrm{~m}^{-1}$ air molecules can become field-ionized. There are several predictable consequences:

(i) injection of positive ions into the air close to ground;

(ii) dielectric breakdown of the air;

(ii) initiation of corona discharges;

(iv) emission of visible light from the discharge plasma;

(v) emission of high frequency electromagnetic (EM) radiation.

Airborne ions are expected to act as nucleation centers for water droplets, providing a possible explanation for the reported occurrences of pre-earthquake haze or ground-hugging fog. Airborne positive ions could also provide a physical basis for the long-sought explanation of why animals reportedly behave abnormally before major earthquakes, an observation, which has been transmitted over centuries in the folklore of peoples living in seismically active regions (Tributsch 1983).

Corona discharges could be the cause of luminous phenomena, so-called earthquake lights, which reportedly precede large seismic events by days, hours and minutes (Derr 1986; StLaurent 2000). During rock impact experiments (Freund 2002) flashes of light were observed coming from the edges of the rock cylinders. They were identified as corona discharges because they also led to bursts in high frequency EM emission, similar to the increase in static noise at $\mathrm{kHz}$ frequencies noted by radio operators and airplane pilots before major earthquakes (Warwick et al. 1982).

\section{5 "Thermal Anomalies" and Stimulated Mid-IR Emission from the Ground}

It costs energy to break the peroxy bond. From electrical conductivity experiments (Freund et al. 1993) we estimate the (thermal) activation energy for the dissociation of the peroxy bond to be about $2.4 \mathrm{eV} \sim 230 \mathrm{~kJ} / \mathrm{mol}$. During application of stress a similar amount of energy must be dispensed to break the peroxy links, provided by the pool of mechanical energy. Conversely, if two p-holes recombine to form again a peroxy bond, this energy or a large fraction of it will be regained.

If p-holes spread out from the source volume and reach the surface, they become trapped at the solid-air interface, leading to the positive surface potential and high electric fields as mentioned above. The trapping is equivalent to forming a surface layer where the p-holes achieve a higher concentration than anywhere else. As a result the probability of p-hole recombination also increases. Because the pairwise p-hole recombination is an exothermal process, 
the energy thus released will be channeled into the newly formed peroxy bonds. This chain of arguments leads to the conclusion that these newly formed peroxy bonds will be "hot", i.e., in a vibrationally highly excited state. There are two ways how these excited $\mathrm{O}^{-}-\mathrm{O}^{-}$bonds can dissipate their excess energy:

(i) by emitting IR photons at the characteristic frequencies of the O-O stretching vibration;

(ii) by partitioning their energy into the adjacent $\mathrm{X}-\mathrm{O}$ bonds, where $\mathrm{X}=\mathrm{Si}^{4+}, \mathrm{Al}^{3+}$ causing them to become vibrationally excited and to emit at characteristic $\mathrm{X}-\mathrm{O}$ frequencies.

We have recently reported on laboratory experiments aimed at measuring the mid-IR emission from large blocks of granite and of anorthosite. While these rocks were being loaded at one end, the IR emission spectrum measured from the surface $30-40 \mathrm{~cm}$ away from the source volume changed instantly (Freund et al. 2002b, 2003). Narrow emission bands were observed in the range of $850-950 \mathrm{~cm}^{-1}(10-11.7 \mu \mathrm{m})$, i.e., at the frequencies of the O-O stretching vibrations. They include bands, which have been tentatively identified as hot bands arising from transitions between vibrationally excited states. If these observations can be confirmed by further measurements planned for 2004, we may have found a physical process to account for the reported pre-earthquake thermal anomalies seen in mid-IR satellite images (Tronin 2002).

\section{CONCLUSIONS}

The discovery that p-holes exist in igneous rocks in an electrically inactive, dormant state but can be activated by stress may lead to a better understanding of pre-earthquake phenomena, which have previously been considered inexplicable or without merit. For our exploratory series of experiments we have chosen quartz-bearing granite and quartz-free anorthosite to demonstrate that the piezoelectricity of quartz is not the controlling property. We provide evidence that stresses activate p-hole charge carriers in both types of rocks. The differences between the granite and the anorthosite cannot be quantified since the conditions under which the data were taken were different.

We also demonstrated that in both rocks, once the p-holes are activated within the source volume, these charge carriers are capable of spreading into surrounding rocks that are essentially stress-free. This outflow is a mechanism, by which ground currents can be generated. Any sustained outflowing p-hole current, however, must couple to a countercurrent that is needed to complete the current loop. Depending on the nature of the coupling, the details of which are still poorly understood, we can conceptualize ground currents that wax and wane. The ensuing ground current pulses would then lead to local magnetic field variations and to EM emissions in the low to very low frequency range as observed prior to major earthquakes.

When p-hole charge carriers reach the ground surface, they are expected to cause other seemingly disjointed phenomena reported to be associated with impending earthquake activity. For instance, by generating high electric fields at the ground-air interface p-holes may lead to ionization and dielectric breakdown of the ground-level air. This could be the reason for groundhugging fog or haze formation and for luminous phenomena known as earthquake lights. If pholes streaming from below pile up at the Earth's surface but cannot be dissipated fast enough, 
they would cause the ground potential to change over large surface areas. Eventually the ground potentials may become strong enough to induce perturbations in the ionosphere. Finally, if pholes recombine at the ground surface, they are expected to release energy. This energy will be deposited primarily into specific vibrationally excited atomic bonds. When these bonds deexcite radioactively, they would emit in the mid-IR region, causing an apparent increase in the radiation temperature of the Earth's surface.

Acknowledgments We thank the NASA Ames Director's Discretionary Fund and the National Imagery and Mapping Agency (NIMA) for supporting this work. A. T. is supported by the Japan Society for the Promotion of Science (JSPS) for Young Scientists. J. K. and J. M. participated under the Summer 2003 NASA Ames Astrobiology Academy program and an REU-NSF grant, respectively. We thank Michael Haas and Patrick Grant, both at the NASA Ames Research Center, for providing needed test equipment.

\section{REFERENCES}

Alperovich, L., and E. Fedorov, 1999: Perturbation of atmospheric conductivity as a cause of the litosphere-ionopshere interaction. In: Hayakawa M. (Ed.), Atmospheric and Ionospheric Electromagnetic Phenomena Associated with Earthquakes, TERRAPUB, Tokyo, 591-596.

Bell, D. R., and G. R. Rossman, 1992: Water in earth's mantle: The role of nominally anhydrous minerals. Science, 255, 1391-1397.

Bernabé, Y., 1998: Streaming potential in heterogenous networks. J. Geophys. Res., 103, 20827-20841.

Chelidze, T. L., and Y. Gueguen, 1999: Electrical spectroscopy of porous rocks: a review-I. Theoretical models. Geophys. J. Inter., 137, 1-15.

Chen, Y. L., J. Y. Chuo, J. Y. Liu, and S. A. Pulinets, 1999: A statistical study of ionospheric precursors of strong earthquakes in the Taiwan area. 24th General Ass. URSI, URSI.

Christensen, N. I., 1996: Poisson's ratio and crustal seismology.J. Geophys. Res., 101, 31393156.

Cliverd, M., C. Rodger, and N. Thomson, 1999: Investigating seismoionospheric effects on a long subionospheric path. J. Geophys. Res., 104, 171-179.

Cress, G. O., B. T. Brady, and G. A. Rowell, 1987: Sources of electromagnetic radiation from fracture of rock samples in the laboratory. Geophys. Res. Lett., 14, 331-334.

Dea, J. J., P. M. Hansen, and W. M. Woerner, 1993: Long-term ELF background noise measurements, the existence of window regions, and applications to earthquake precursor emission studies. Phys. Earth Planet. Interiors, 77, 109-125.

Dea, J. Y., P. M. Hansen, and W. M. Boerner,1997: ULF/ELF polarimetry: observations of anomalous ULF signals preceding the Northridge earthquake of January 17, 1994. In: Mott H. and W. M. Woerner (Eds.), Wideband Interferometric Sensing and Imaging Polarimetry, SPIE. 3120,195-206. 
Derr, J. S., 1986: Luminous phenomena and their relationship to rock fracture. Nature, 321, 470-471.

Dieckmann, R., C. A. Witt, and T. O. Mason, 1983: Defects and cation diffusion in magnetite $(\mathrm{V})$ : Electrical conduction, cation distribution and point defects in $\mathrm{Fe}_{3-\mathrm{d}} \mathrm{O}_{4}$. Ber. Bunsenges. Phys. Chem., 87, 495-503.

Duba, A. G., and T. J. Shankland, 1982: Free carbon and electrical conductivity in the Earth's mantle. Geophys. Res. Lett., 9, 1271-1274.

Finkelstein, D., U. S. Hill, and J. R. Powell, 1973: The piezoelectric theory of earthquake lightning. J. Geophys. Res., 78, 992-993.

Fraser-Smith, A. C., 1992: ULF, ELF, and VLF electromagnetic field observations during earthquakes: Search for precursors. Low Frequency Electrical Precursors: Fact of Fiction?, Lake Arrowhead, CA, June 14-17, 1992, NSF Natl. Earthquake Hazard Reduction Program.

Freund, F., 2002: Charge generation and propagation in rocks. J. Geodynamics, 33, 545-572.

Freund, F., E. J. Whang, F. Batllo, L. Desgranges, C. Desgranges, and M. M. Freund, 1994: Positive hole - type charge carriers in oxide materials. Grain Boundaries and Interfacial Phenomena in Electronic Ceramics. L. M. Levinson. Cincinnati, OH, Amer. Ceram. Soc., 263-278.

Freund, F., J. T. Dickinson and M. Cash, 2002a: Hydrogen in rocks: An energy source for deep microbial communities. Astrobiology, 2, 83-92.

Freund, F., M. M. Freund, and F. Batllo, 1993: Critical review of electrical conductivity measurements and charge distribution analysis of magnesium oxide.J. Geophys. Res., 98 , 22209-22229.

Freund, F., D. Ouzounov, M. M. Freund, Z. Wan, Y. Zhang, Q. Zhang, M. Jhabvala, A. La, M. McClare, A. Velle, Y. Fei and S. C. Tsay, 2002b: Mid-Infrared radiation, electric charges and acoustic emission during rock deformation. Fall Meeting, Washington, DC, Amer. Geophys. Union.

Freund, F. T., 2003: On the electrical conductivity structure of the stable continental crust.J. Geodyn., 35, 353-388.

Freund, F. T., D. Ouzounov, Z. Wan, Y. Zhang, Q. Zhang, R. Post, J. Keefner, J. Mellon, and A. Al-Manaseer, 2003: Stimulated IR emission from the surface of rocks during deformation. AGU Fall Metting.

Friebele, E. J., D. L. Griscom, M. Stapelbroek, and R. A. Weeks, 1979: Fundamental defect centers in glass: The peroxy radical in irradiated high-purity fused silica. Phys. Rev. Lett., 42, 1346-1349.

Frost, B. R., W. S. Fyfe, K. Tazaki, and T. Chan, 1989: Grain boundary graphite in rocks and implications for high electrical conductivity in the lower crust. Nature, 340, 134-138.

Fukuchi, T., 1996: A mechanism of the formation of $\mathrm{E}^{\prime}$ and peroxy centers in natural deformed quartz. Appl. Radiat. Isot., 47, 1509-1521.

Gershenzon, N., and G. Bambakidis, 2001: Modeling of seismo-electromagnetic phenomena. Rus. J. Earth Sci., 3, 247-275.

Glover, P. W. J., and F. J. Vine, 1992: Electrical conductivity of carbon-bearing granulite at raised temperatures and pressures. Nature, 360, 723-726, 1992. 
Glover, P. W. J., and F. J. Vine, 1994: Electrical conductivity of the continental crust.Geophys. Res. Lett., 21, 2357-2360.

Haken, H., 1978: Synergetics: Non-Equilibrium Phase Transitons and Self-Organization in Physics, Chemistry and Biology. Heidelberg, Springer Verlag.

Hanson, D. R., and H. A. Spetzler, 1994: Transient creep in natural and synthetic, iron-bearing olivine single crystals: Mechanical results and dislocation microstructures. Tectonophysics, 235, 293-315.

Hayakawa, M., and O. A. Molchanov, 1998: On the generation mechanism of ULF seismogenic electromagnetic emissions. Phys. Earth Planet. Inter., 105, 201-210.

Henderson, B., and J. E. Wertz, 1977: Defects in the Alkaline Earth Oxides. London, Taylor \& Francis.

Hermance, J. F., 1979: The electric conductivity of materials containing partial melt: a simple model from Archie's law. Geophys. Res. Lett., 6, 613-616.

Huang, Q., and M. Ikeya, 1998: Seismic electromagnetic signals (SEMS) explained by a simulation experiment using electromagnetic waves. Phys. Earth Planet. Inter., 109, 107-114.

Ismaguilov, V. S., Y. A. Kopytenko, K. Hattori, P. M. Voronov, O. A. Molchanov, and M. Hayakawa, 2001: ULF magnetic emissions connected with under sea bottom earthquakes. Natur. Haz. Earth Sys. Sci., 1, 23-31.

King, B. V., and F. Freund, 1984: Surface charges and subsurface space charge distribution in magnesium oxide containing dissolved traces of water. Phys. Rev., B 29, 5814-5824.

Kittel, C., 1980: Introduction to Solid State Physics. New York, J. Wiley \& Sons.

Liu, J. Y., Y. I. Chen, S. A. Pulinets, Y. B. Tsai, and Y. J. Chuo, 2000: Seismo-ionospheric signatures prior to $\mathrm{M} \geq 6.0$ Taiwan earthquakes. Geophys. Res. Lett., 27, 3113-3116.

Liu, J. Y., Y. I. Chen, Y. J. Chuo, and H. F. Tsai, 2001: Variations of ionospheric total electron content during the Chi-Chi earthquake. Geophys. Res. Lett., 28, 1383-1386.

Lonre, B., F. Perrier, and J.-P. Avouac, 1999: Streaming potential measurements, 2: Relationship between electrical and hydraulic flow patterns from rock samples during deformation. J. Geophys. Res., 104, 17879-17896.

Matsushima, S., 1989: Partial melting of rocks observed by the sound velocity method and the possibility of a quasi-dry low velocity zone in the upper mantle.Phys. Earth Planet. Inter., 55, 306-312.

Merzer, M., and S. L. Klemperer, 1997: Modeling low-frequency magnetic-field precursors to the Loma Prieta earthquake with a precursory increase in fault - zone conductivity. Pure Appl. Geophys., 150, 217-248.

Miguel, M. C., A. Vespignani, S. Zapperi, J. Weiss, and J. R. Grasso, 2001: Intermittent dislocation flow in viscoplastic deformation. Nature, 410, 667-671.

Molchanov, O. A., and M. Hayakawa, 1998a: On the generation mechanism of ULF seimogenic electromagnetic emissions. Phys. Earth Planet. Inter., 105, 201-220.

Molchanov, O. A., and M. Hayakawa, 1998b: Subionospheric VLF signal perturbations possibly related to earthquakes. J. Geophys. Res., 103, 17489-17504. 
Molchanov, O. A., M. Hayakawa, T. Oudoh, and E. Kawai, 1998c: Precursory effects in the subioniospheric VLF signals for the Kobe earthquake. Phys. Earth Planet. Inter., 105, 239-248.

Molchanov, O. A., O. A. Mazhaeva, A. N. Goliavin, and M. Hayakawa, 1993: Observation of the Intercosmos-24 satellite of ELF-VLF electromagnetic emissions associated with earthquakes. Ann. Geophysicae., 11, 431-440.

Morgan, F. D., E. R. William, and T. R. Madden, 1989: Streaming potential properties of Westerly granite with applications. J. Geophys. Res., 94, 12449-12461.

Nitsan, U., 1977: Electromagnetic emission accompanying fracture of quartz-bearing rocks. Geophys. Res. Lett., 4, 333-336.

Ohta, K., K. Umeda, N. Watanabe, and M. Hayakawa, 2001: ULF/ELF emissions observed in Japan, possibly associated with the Chi-Chi earthquake in Taiwan. Natur. Haz. Earth Sys. Sci., 1, 37-42.

Oike, K., and T. Ogawa, 1986: Electromagnetic radiation from shallow earthquakes observed in the LF range. J. Geomagn. Geoelectr., 38, 1031-1049.

Park, S. K., 2002: Enhanced mantle conductivity from sulfides beneath the Sierra Nevada? AGU Fall Meeting.

Park, S. K., M. J. S. Johnston, T. R. Madden, F. D. Morgan, and H. F. Morrison, 1993: Electromagnetic precursors to earthquakes in the ULF band: a review of observations and mechanisms. Rev. Geophys., 31, 117-132.

Parrot, M., 1994: Statistical study of ELF/VLF emissions recorded by a low-altitude satellite during seismic events. J. Geophys. Res., 99, 23339-23347.

Pulinets, S., and K. Boyarchuk, 2004: Ionospheric Precursors of Earthquakes. Heidelberg, Springer.

Pulinets, S. A., K. A. Boyarchuk, V. Hegai, C. Kim, and A. Lomonosov, 2000: Quasielectrostatic model of atmosphere-thermosphere-ionosphere coupling.Adv. Space Res., 26, 1209-1218.

Revil, A., H. Schwaeger, L. M. Cathles, and P. D. Manhardt, 1999: Streaming potential in porous media, 1, Theory and application to geothermal systems.J. Geophys. Res., 104, 20033-20048.

Ricci, D., G. Pacchioni, M. A. Szymanski, A. L. Shluger. and A. M. Stoneham, 2001: Modeling disorder in amorphous silica with embedded clusters: The peroxy bridge defect center. Physical Rev., B 64, 224,104-1-224,104-8.

Rossman, G. R., 1996: Studies of OH in nominally anhydrous minerals. Phys. Chem. Miner., 23, 299-304.

Serebryakova, O. N., S. V. Bilichenko, V. M. Chmyrev, M. Parrot, J. L. Rauch, F. Lefeuvre, and O. A. Pokhotelov, 1992: Electromagnetic ELF radiation from earthquake regions as observed by low-altitude satellites. Geophys. Res. Lett., 19, 91-94.

Shankland, T. J., A. G. Duba, E. A. Mathez, and C. L. Peach, 1997: Increase in electrical conductivity with pressure as an indicator of conduction through a solid phase in midcrustal rocks. J. Geophys. Res., 102, 14741-14750. 
Sorokin, V. M., V. M. Chmyrev, and A. K. Yaschenko, 2001: Electrodynamic model of the lower atmosphere and the ionosphere coupling. J. Atmosp. Solar-Terrest. Phys., 63, 1681-1691.

St-Laurent, F., 2000: The Saguenay, Québec, earthquake lights of November 1988-January 1989. Seismol. Res. Lett., 71, 160-174.

Sze, S. M., 1981: Physics of Semiconductor Devices. New York, NY, Wiley.

Takeuchi, A., and H. Nagahama, 2001: Voltage changes induced by stick-slip of granites. Geophys. Res. Lett., 28, 3365-3368.

Takeuchi, A., and H. Nagahama, 2002: Interpretation of charging on fracture or frictional slip surface of rocks. Phys. Earth Planet. Inter., 130, 285-291.

Tributsch, H., 1983: When Snakes Awake: Animals and Earthquake Prediction. Cambridge, Mass., MIT Press.

Tronin, A. A., 2002: Atmosphere-lithosphere coupling: Thermal anomalies on the Earth surface in seismic process. In: Hayakawa M.,and O. A. Molchanov (Eds.), SeismoElectromagnetics: Lithosphere-Atmosphere-Ionosphere Coupling, TERRAPUB, Tokyo, 173-176.

Troyan, V. N., and Y. V. Kiselev, 2001: Estimation of reliability of seismic and electromagnetic monitoring in seismic active areas by diffraction tomography. Natur. Haz. Earth Sys. Sci., 1, 69-73.

Vallianatos, F., and A. Tsanis, 1998: Electric current generation associated with the deformation rate of a solid: Preseismic and coseismic signals. Phys. Chem. Earth., 23, 933-938.

Vershinin, E. F., A. V. Buzevich, K. Yumoto, K. Saita, and Y. Tanaka, 1999: Correlation of seismic activity with electromagnetic emissions and variations in Kamchatka region. In: In: Hayakawa M. (Ed.), Atmospheric and Ionospheric Electromagnetic Phenomena Associated with Earthquakes, TERRAPUB, Tokyo, 513-517.

Warwick, J. W., C. Stoker, and T. R. Meyer, 1982: Radio emission associated with rock fracture: Possible application to the great Chilean earthquake of May 22, 1960. J. Geophys. Res., 87, 2851-2859.

Wilkins, R. W. T., and W. Sabine, 1973: Water content of some nominally anhydrous silicates. Amer. Miner., 58, 508-516.

Yamada, I., K. Masuda, and H. Mizutani, 1989: Electromagnetic and acoustic emission associated with rock fractures. Phys. Earth Planet. Inter., 57, 157-168.

Yoshida, S., O. C. Clint, and P. R. Sammonds, 1998: Electrical potential changes prior to shear fracture in dry and saturated rocks. Geophys. Res. Lett., 25, 1577-1580.

Yoshida, S., P. Manjgaladze, D. Zilpimiani, M. Ohnaka, and M. Nakatani, 1994: Electromagnetic emissions associated with frictional sliding of rock. In: Hayakawa M., and Y. Fujinawa (Eds.), Electromagnetic Phenomena Related to Earthquake Prediction, TERRAPUB,1 Tokyo, 307-322. 